\title{
Some Stylized Facts of Short-Term Stock Prices of Selected Nigerian Banks
}

\author{
Maruf Ariyo Raheem*, Patrick Oseloka Ezepue \\ Statistics, Information Modelling, and Financial Mathematics Research Group, Department of Engineering and Mathematics, \\ Sheffield Hallam University, Sheffield, United Kingdom \\ Email: ^rahemarsac@yahoo.com, patrick.ezepue@sky.com
}

How to cite this paper: Raheem, M.A. and Ezepue, P.O. (2018) Some Stylized Facts of Short-Term Stock Prices of Selected Nigerian Banks. Open Journal of Statistics, 8 , 94-133.

https://doi.org/10.4236/ojs.2018.81008

Received: September 27, 2017

Accepted: February 3, 2018

Published: February 6, 2018

Copyright (c) 2018 by authors and Scientific Research Publishing Inc. This work is licensed under the Creative Commons Attribution International License (CC BY 4.0).

http://creativecommons.org/licenses/by/4.0/

\section{c) (i) Open Access}

\begin{abstract}
This paper examines presence of some stylized facts of short-term stock prices in the banking sector of the Nigerian Stock Market (NSM). Non-normality, lack of autocorrelation in the returns at first lag and significant positive autocorrelation in higher magnitude returns, widely studied in other markets, are investigated using daily closing stock prices of the four major Nigerian banks (Access, First, Guaranty Trust and United Bank for Africa (UBA)), from 2001 to 2013; encompassing periods of different financial scenarios. Jarque-Bera (JB), Doonik-Hansen, Kolmogrov-Smirnov and Ljung-Box (Q) test statistics are applied. Our findings reveal that the four banks stocks behave slightly different, but generally possess the stylized facts found in other markets. Observed is that, while the distributions of the returns for two of these banks (First and UBA) are approximately symmetric and leptokurtic; those of Access and Guaranty Trust banks are significantly non-symmetric and leptokurtic, thus non-normally distributed. Also established is that, while autocorrelation functions of daily returns are either negative or zero, those of both absolute returns and the squared returns are mostly positive. The autocorrelations of absolute returns are found to be predominantly positive and more persistent than those of the squared returns; indicating volatility clustering. Consequently, we conclude that the short-term stock prices of these banks behave like those of other markets. Some implications of the results for financial investment and stock market behaviour in the banking sector of NSM are discussed.
\end{abstract}

\section{Keywords}

Stylized Facts, Nigerian Stock Market (NSM), Banking Sector, Non-Normality, Volatility Clustering, SSMCD 


\section{Introduction}

Following the 2004 bank restructuring, related financial reforms in Nigeria, and the 2007-09 global financial crisis, the Nigerian financial market experienced near bank failures which were prevented by proactive interventions by the Central Bank of Nigeria (CBN). There has also been a dramatic fall (more than 60\%) in the market capitalisation of the Nigerian Stock Market (NSM) between 2008 and 2009. These fluctuations make the study of volatility in NSM returns topical, especially in light of financial reforms, investment and risk management [1], financial policy [2], economic development, and stock market development, linked to GDP growth, competitiveness, market microstructure, and macroeconomic policy setting [3]-[10].

Despite the ubiquity of volatility studies such as these in Nigeria and elsewhere, there is a dearth of studies which are focused specifically on the link between stylized facts of bank stock returns and some aspects of volatility. This link is particularly important because the distributions of returns underpin volatility and financial modelling of investment assets. This paper fills this empirical gap and anticipates related future work in systematic stock market characterisation and development (SSMCD) [11] [12], for example, argue that Nigerian policy makers need to understand the volatilities in the financial system at overall market, sector- and company-specific levels, in order to gear monetary, macroeconomic and fiscal policies towards enhancement of economic performance, GDP growth, competitiveness and asset price stability; see also Aliyu [4]. Therefore, the focal point of SSMCD work to which this study belongs is the need to model the underlying distributions of stock returns in key sectors of the NSM, for example, and their implications for financial policy. The choice of the banking sector in this paper is because it is by far the most dominant sector of the NSM. Further rationale for the paper and its focus on Nigeria as a developing country is provided later in this introduction.

We note that even though the paper is based on four main Nigerian banks, the results would seem to provide a good insight into the nature of stylized facts of bank returns generally. This is because bank stocks typically correlate significantly since they use interbank lending rates in their investment decisions and are subject to similar CBN financial and corporate governance regulations. Moreover, the selected banks have been in the market for fairly long periods and generally monitor each other's financial innovations, for which reason their performance would indicate the general pulse of the banking sector of the NSM. Based on insights from this paper, future work will explore possible differences in stylized facts of the entire sector.

With particular reference to stylized facts, the purpose of modelling financial data is to approximate the behaviour of the unobservable data generating process (DGP) that determines observed stock prices [13]. Thus, the process of examining how fit this approximation is to the data leads to identifying the "stylised facts" of stock returns. A stylised fact is a statistical property that is expected 
to be found in any series of observed stock prices or returns [14] [15]. Hence, if a model is set to approximate the behaviour of asset returns, then it should as much possible capture these facts.

Several studies have investigated the dynamic nature of major stock markets (at both developed and emerging level), with the discovery of some number of stylized facts. It has been observed that the empirical distributions of stock returns appear to be excessively leptokurtic, thereby making the returns non-normally distributed (see: [16] [17] [18] [19]). Also noticed is that short-term stock returns exhibit volatility clustering; this according to Mandelbrot [16] implies that "large changes tend to be followed by large changes, of either sign, and small changes tend to be followed by small changes". The characteristic that has successfully been modelled using ARCH-GARCH type models (see: [20] [21] [22] [23]). Another stylized fact is that changes in stock prices tend to be negatively related to changes in volatility [24] [25] [26]; better put, it means negative returns (fall in prices) are followed by greater volatility than do positive returns (increase in prices) of the same magnitude. In some contexts this is referred to as "Asymmetric effect". First-order autocorrelation of stock index was also identified to be negatively related to the level of volatility [27] [28] [29].

Meanwhile, most of the works thus far have focused on developed financial markets with few exceptions (see [30]). For investors seeking opportunities in emerging markets however, a better understanding of the stock return behaviour is of great interest. One such promising market that has received less than expected attention (as far as we know) is the Nigerian Stock Market (NSM). The NSM with its position and potentials in African and World markets has progressed tremendously in recent years, especially after surviving the 2007-2009 financial crises. Consequently, a better understanding of its stock market should be of interest to both local and foreign investors. Specifically, it would be useful to examine whether stylized facts, which are present in the developed markets also characterize the behaviour of the NSM. More importantly, returns on the NSM, like many other emerging markets have been found to have low (in some years even negative) correlation with the returns of major developed markets, providing opportunities for substantial risk reduction through diversification to international investors [31].

Also noted is that the daily returns from most emerging markets (including Nigeria) are found to depart from normal distribution [32]. Thus, understanding the stochastic behaviour of the NSM is vital for both international as well as local investors and may point out interesting similarities and differences between the NSM and developed stock markets. Thus far, there has been no empirical study that methodically investigates the short-term dynamics of stock returns in the NSM despite the potential importance of this market to investors. This research investigates if the stylized facts which have been associated with asset returns behaviour in most climes, especially the developed markets and some emerging 
markets, also characterise the behaviour of stocks in Nigeria.

Of particular interest are the three major facts identified by Taylor [33] and a few other researches, which are more peculiar to daily returns, namely: 1) the distribution of returns is non-normal; 2) correlations between the magnitudes of returns over short-time periods are positive and statistically significant; 3 ) and lack of correlation between the returns of different days. To fulfil the set targets, four major and investing banks have been chosen for our study.

The main objectives of the paper are: 1) to explore the distributional characteristics of the stylized facts of bank stock returns, namely normality tests, serial correlations in stock returns, and serial correlations in volatility; and 2) to link the results to possible differences in banks' returns stability and/or performance in periods of bank reforms and global financial crisis. These basic stylised facts will foreshadow detailed distributional characterisations envisaged in future work, which will look at the whole banking sector and therefore enable the researchers to identify possible differences in underlying returns distributions across banks with different banking mandates and business models. The wider SSMCD line of work to which the paper belongs is described in more detail in the following literature review.

\section{Literature Review}

The focus of this literature review is to delineate current knowledge on stylized facts, clarify the aspects of key interest in this paper, and the gaps in knowledge they relate to. It has been observed that the empirical distribution of stock returns appears to be excessively leptokurtic, thereby making the returns to be described via non-normal distribution (see: [16] [17] [18] [19] [34]). Particularly, the empirical distributions of most daily stock return series tend to be leptokurtic and skewed than would be of a normal distribution ([14] [35] [36]). That is, daily return series are known for having heavy tails and highly peaked centre.

Fama [17] by examining the daily returns data spanning from 1957 to1962 on 30 stocks obtained from DJIA (Dow Jones Industrial Average) concluded that daily stock returns are undoubtedly leptokurtic; with the same view shared by Pagan [35] and Cont. [15]. The strength of the leptokurtosis in monthly series was rather found to be weaker [14] [15] [36].

It is, however, noted that the lack of significant autocorrelation in the daily returns does not make the series to be independent. This is simply because of the presence of significant autocorrelation in the series of absolute and squared returns for several lags, especially for most daily stock returns. Ding et al. [37] found positive autocorrelation in the returns of both squares and absolute returns for lags running to thousands; the situation that is referred to as Volatility Clustering. Specifically, short-term interval stock returns (e.g. intra-daily, daily and weekly) exhibit volatility clustering; according to Mandelbrot [16], this implies that "large changes tend to be followed by large changes, of either sign, and small changes tend to be followed by small changes". Taylor [33] presents the 
observation made by Mandelbrot [16], which was confirmed by Fama [17] that compared to small absolute returns, large absolute returns are likely to be followed by large absolute returns. The finding was however not alone satisfactory enough in predicting the direction of price changes.

It is claimed that daily returns for liquid stocks exhibit non-significant (linear) autocorrelation at various lags [14] [15] [35] [37]; Aggarwal et al., (38) however notice the significant autocorrelation in daily returns of some markets (whose stocks are known to be illiquid) in Latin America and Asia between 1985 and 1995. Cont. [15] and Taylor [39] found that intra-daily returns of liquid stocks for periods more than $20 \mathrm{~min}$. do not exhibit significant autocorrelations, whereas those of shorter periods reflected negative autocorrelation. This according to them might be due to the effect of market microstructure. It is believed that while very little autocorrelation is present in the series of returns $\left\{r_{t}\right\}$ itself, substantially more autocorrelation is found in the series of absolute returns $\left\{\left|r_{t}\right|\right\}$. The autocorrelation of absolute returns are always positive at a lag of one day and positive dependence continues to be found for several lags [33]. It is also noted that the dependency level displayed by $\left\{\left|r_{t}^{2}\right|\right\}$ is generally less in degree compared to that which is attributed to absolute returns.

Taylor [33], however, concludes that all the aforementioned features apply to any long series of the daily returns for financial assets that are traded frequently. In general, the distributions of daily returns especially are found to be approximately symmetric, but with high kurtoses, fat tails, and peaked centres compared to the normal distribution. Also, while autocorrelations of daily returns are close to zero (or mostly negative), those of absolute (and probably squared) returns are positive for several lags, which substantially indicates more linear dependence in the autocorrelations of the latter than do the former. This level of dependence in the absolute as well as the squared returns, according to Taylor [14], is responsible for slow changes in the returns volatility. Furthermore, according to many studies, periods when the returns are relatively more variable are followed by relatively high expected absolute returns, whereas those periods with relatively less variable returns result into having relatively low expected absolute returns.

In the light of the above and in line with the objectives of this study, this paper considers the foundational distributional characteristics of the stylized facts of the bank stock returns, namely normality tests, serial correlations in stock returns, and serial correlations in volatility which complement the directions. It also attempts to relate to results to share price behaviours of the banks in different periods of financial reforms and global financial crisis. These basic stylised facts will inform detailed distributional characterisation envisaged in future work which will look at the whole banking sector and therefore enable the researchers to identify possible differences in underlying returns distributions across banks with different banking mandates and business models.

The paper builds on the results obtained by Omar [11] and Ezepue and Omar 
[12] which use the All-Share Market Index data from the NSM for periods encompassing the 2004 reforms and the 2007 global financial crisis. The results of which should have important implications for investment analysis, financial policy, stock market development, and financial engineering within the banking sector and the NSM generally [11] [12].

\section{Methodology}

This section presents brief account on the data source and our choice of the four banks; and the techniques used in achieving the objective of this research. Firstly, a brief discussion on how returns are being generated is provided and secondly, various statistical tests and methods adopted in achieving the aim of this research are presented.

\subsection{Data Presentation}

The data used in this research were obtained from the Cash craft's website (http://www.cashcraft.com/), a subsidiary of the Nigerian stock Exchange (NSE), are daily closing stock prices for four banks frequently trading with NSE, ranging from $2^{\text {nd }}$ January, 2001 to $31^{\text {st }}$ December, 2013, making up a total of 3201 (Access), 3200 (First), 3203 (Guaranty) and 3202 (UBA) observations. Our choice of these banks was informed by the fact that they are among the leading trading banks with very high market capitalizations, and are banks which in spite of various difficulties experienced in the Nigerian financial system have maintained their original name. Also, while two of these banks, Access and UBA, have at one time merged with other banks, First Bank and Guaranty Trust never merged with any other banks.

Meanwhile, Tables 1-4 below present sample data on the first 10 trading days across the four banks-Access, First, Guaranty and UBA respectively.

Having obtained the data continuously compounded (or geometric or log) returns, absolute, mean-adjusted and squared returns are then computed from the closing prices of the four banks and used in the analyses.

The returns are generated from the stock prices using the formula:

$$
r_{t}=\log \left(R_{t}\right)=\log \left(P_{t}\right)-\log \left(P_{t-1}\right)=p_{t}-p_{t-1}
$$

where $R_{t}$, is the simple return at time $t$, derived as:

$$
R_{t}=\frac{P_{t}-P_{t-1}}{P_{t-1}}, P_{t} \text { is the stock closing price at time } t \text { and } P_{t-1} \text { closing price at }
$$

time $t-1 ; r_{t}$ is called geometric or continuously compounded return; used for analysing stock data, $p_{t}$ is the log of price at time " $t$ " and $p_{t-1}$ is the log of price at time " $t-1$ " period preceding time " $t$ ".

\section{Mean-Adjusted Returns}

Suppose the mean returns is obtained as

$$
\bar{r}(\text { or } r)=\frac{1}{T} \sum_{t=1}^{T} r_{t}
$$


Table 1. Access Bank's 1st 10 trading days.

\begin{tabular}{ccccc}
\hline Day & Date & Price & LN price & RETURN \\
\hline 1 & $02 / 01 / 2001$ & 1.41 & 0.34359 & NA \\
2 & $03 / 01 / 2001$ & 1.34 & 0.29267 & -0.05092 \\
3 & $04 / 01 / 2001$ & 1.34 & 0.29267 & 0 \\
4 & $05 / 01 / 2001$ & 1.34 & 0.29267 & 0 \\
5 & $08 / 01 / 2001$ & 1.34 & 0.29267 & 0 \\
6 & $09 / 01 / 2001$ & 1.3 & 0.262364 & -0.03031 \\
7 & $10 / 01 / 2001$ & 1.3 & 0.262364 & 0 \\
8 & $11 / 01 / 2001$ & 1.3 & 0.262364 & 0 \\
9 & $12 / 01 / 2001$ & 1.36 & 0.307485 & 0.04512 \\
10 & $17 / 01 / 2001$ & 1.36 & 0.307485 & 0 \\
\hline
\end{tabular}

Table 2. First Bank's 1st 10 trading days.

\begin{tabular}{ccccc}
\hline Day & Date & Price & LN Price & RETURNS \\
\hline 1 & $02 / 01 / 2001$ & 24 & 3.178054 & NA \\
2 & $03 / 01 / 2001$ & 24.25 & 3.188417 & 0.010363 \\
3 & $04 / 01 / 2001$ & 23.09 & 3.1394 & -0.04902 \\
4 & $05 / 01 / 2001$ & 23.09 & 3.1394 & 0 \\
5 & $08 / 01 / 2001$ & 23.09 & 3.1394 & 0 \\
6 & $09 / 01 / 2001$ & 25.3 & 3.230804 & 0.091405 \\
7 & $10 / 01 / 2001$ & 26.56 & 3.279406 & 0.048602 \\
8 & $11 / 01 / 2001$ & 27.25 & 3.305054 & 0.025647 \\
9 & $12 / 01 / 2001$ & 28.61 & 3.353756 & 0.048703 \\
10 & $17 / 01 / 2001$ & 28.75 & 3.358638 & 0.004881 \\
\hline
\end{tabular}

Table 3. GTB's 1st 10 trading days.

\begin{tabular}{ccccc}
\hline Trading Days & Date & Price & LN Price & RETURNS \\
\hline 1 & $02 / 01 / 2001$ & 4.17 & 1.427916 & NA \\
2 & $03 / 01 / 2001$ & 4.35 & 1.470176 & 0.042259809 \\
3 & $04 / 01 / 2001$ & 4.56 & 1.517323 & 0.047146778 \\
4 & $05 / 01 / 2001$ & 4.35 & 1.470176 & -0.047146778 \\
5 & $08 / 01 / 2001$ & 4.4 & 1.481605 & 0.011428696 \\
6 & $09 / 01 / 2001$ & 4.21 & 1.437463 & -0.044141893 \\
7 & $10 / 01 / 2001$ & 4.4 & 1.481605 & 0.044141893 \\
8 & $11 / 01 / 2001$ & 4.57 & 1.519513 & 0.037908664 \\
9 & $12 / 01 / 2001$ & 4.78 & 1.564441 & 0.044927342 \\
10 & $17 / 01 / 2001$ & 5.37 & 1.680828 & 0.116387362 \\
\hline
\end{tabular}


Table 4. UBA's 1 st 10 trading days.

\begin{tabular}{ccccc}
\hline Trading Days & Date & Price & Log Price & RETURNS \\
\hline 1 & $02 / 01 / 2001$ & 14.5 & 2.674149 & NA \\
2 & $03 / 01 / 2001$ & 15.22 & 2.72261 & 0.048461703 \\
3 & $04 / 01 / 2001$ & 15.98 & 2.771338 & 0.048727588 \\
4 & $05 / 01 / 2001$ & 16.5 & 2.80336 & 0.032022441 \\
5 & $08 / 01 / 2001$ & 14.44 & 2.670002 & -0.13335825 \\
6 & $09 / 01 / 2001$ & 14 & 2.639057 & -0.0309448 \\
7 & $10 / 01 / 2001$ & 14.7 & 2.687847 & 0.048790164 \\
8 & $11 / 01 / 2001$ & 15.43 & 2.736314 & 0.048466173 \\
9 & $12 / 01 / 2001$ & 16.18 & 2.783776 & 0.047462245 \\
10 & $17 / 01 / 2001$ & 18.71 & 2.929058 & 0.145282229 \\
\hline
\end{tabular}

where $T$ is the total number of observations.

Then the mean-adjusted return is obtained as:

$$
\tilde{r}_{t}=\left(r_{t}-\bar{r}\right)
$$

From (3.2), we obtain absolute returns as: $\left|\tilde{r}_{t}\right|$, which is the absolute value of the mean-adjusted returns.

Squaring both sides of (3.2), we have the squared returns: $\tilde{r}_{t}^{2}=\left(r_{t}-\bar{r}\right)^{2}$.

Having obtained the (log) returns from the closing stock price of each of the banks and derived the mean-adjusted returns, absolute and squared returns from the (log) returns; we on proceed to discussing the different tests to be implemented in addressing the set objectives for the study.

\section{Remark}

Note that the " $\log ()$ " function used in (3.1) is logarithm to base " $e$ ", mostly referenced as "ln()" function; which is called "natural logarithm" function.

\subsection{Normality Tests}

Mandelbrot [16] considered two related issues as regards the returns distribution in finance. These are:

1) Does the normality assumption hold for equity returns? 2) To what extents are returns non-normal?

Various tests of normality have been developed based on, moments of the return series, the density function of the distribution, or properties of ranked series.

To consider tests based on the properties of the original distribution of return, we restrict ourselves to tests based on moments and density function of the returns, with a view to accomplishing the first objective of this research; further details of which are presented as follows.

\section{Tests based on Moments}

The most widely used test due to Jarque and Bera [40] and Bera and Jarque 
[41], relies on the fact that for a normal distribution both the skewness $(\hat{s})$ and excess kurtosis $(\hat{k}-3)$ should be equal to zero.

\section{Skewness}

The sample coefficient of skewness, which is a measure of symmetry of the return series, is computed using the formula:

$$
\hat{S}=\frac{1}{T} \sum_{t=1}^{T}\left[\frac{r_{t}-\bar{r}}{s}\right]^{3}
$$

\section{Kurtosis}

The sample coefficient of kurtosis, which determines the tail thickness of the return's distribution, is obtained as:

$$
\hat{K}=\sqrt{\frac{1}{T}} \sum_{t=1}^{T}\left[\frac{r_{t}-\bar{r}}{s}\right]^{4}
$$

Jarque and Bera [40] propose the following asymptotic distributions for the two moments:

$$
\begin{aligned}
& t=\frac{\hat{s}}{\sqrt{\frac{6}{T}}} \approx N(0,1) \\
& t=\frac{\hat{k}-3}{\sqrt{\frac{24}{T}}} \approx N(0,1)
\end{aligned}
$$

Subject to this, they propose the $J B$ test statistic defined as:

$$
J B=T \frac{\hat{s}^{2}}{6}+\frac{(\hat{k}-3)^{2}}{24} \approx \chi_{(2)}^{2}
$$

For testing normality, where $\hat{S}$ is the sample skewness, $\hat{K}$ the sample kurtosis and $T$ the sample size. Null hypothesis $\left(H_{0}\right)$ of normality is rejected in favour of Alternative hypothesis $\left(H_{1}\right)$ of Non-normality if the $p$-value of the JB statistic is less than the set significance level ( $\alpha=0.05$ for example). Although this is most widely used in finance, it does have two limitations: 1 ) it only holds for very large samples; to correct this bias, Doornik and Hansen [42] provide an omnibus test for normality. 2) The empirical skewness and kurtosis are computed for given values of mean and variance, which are both subject to sampling errors. Doornik and Hansen [42] first obtain approximations for the finite sample distributions of skewness and kurtosis under normality assumption, coupled with assumptions that the kurtosis follows a Gamma distribution and that $\hat{k}>1+\hat{s}^{2}$. They show that with the normality assumption,

$$
\tilde{W}=z_{1}^{2}+z_{2}^{2} \approx \chi_{(2)}^{2}
$$

where $z_{1}$ and $z_{2}$ are respectively denoted as the finite-sample skewness and kurtosis, and computed as:

$$
z_{1}=\frac{1}{\sqrt{\log (\omega)}} \log \left(g+\sqrt{1+g^{2}}\right)
$$




$$
z_{2}=\left[\left(\frac{\chi}{2 \alpha}\right)^{1 / 3}-1+\frac{1}{9 \alpha}\right] \sqrt{9 \alpha}
$$

Here

$$
\begin{gathered}
g=\hat{s}^{2} \sqrt{\frac{\omega^{2}-1}{2} \frac{(T+1)(T+3)}{6(T-2)}} \\
\omega^{2}=-1+\sqrt{2\left(b_{0}-1\right)} \chi=2 b_{1}\left(\hat{k}-1-\hat{s}^{2}\right) \\
\alpha=b_{2}+b_{3} \hat{s}^{2}
\end{gathered}
$$

With the following correction factors for finite sample:

$$
\begin{gathered}
b_{0}=\frac{3\left(T^{2}+27 T-70\right)(T+1)(T+3)}{(T-2)(T+5)(T+7)(T+9)} \\
b_{1}=\frac{(T+5)(T+7)\left(T^{3}+37 T^{2}+11 T-313\right)}{12 \tau} \\
b_{2}=\frac{(T-2)(T+5)(T+7)\left(T^{2}+27 T-70\right)}{6 \tau} \\
b_{3}=\frac{(T-7)(T+5)(T+7)\left(T^{2}+2 T-5\right)}{6 \tau} \\
\tau=(T-3)(T+1)\left(T^{2}+15 T-4\right)
\end{gathered}
$$

\section{Tests based on the Density functions}

In this case, the Kolmogorov-Smirnov (KS) that compares the empirical cumulative density function $(c d f), F_{r}($.$) of the returns with the c d f$ of normal distribution (or any other assumed distribution), $F^{*}($.$) (with the parameter$ vector $\theta$ ) is used. Since the true distribution of $F_{r}($.$) is unknown, it is ap-$ proximated using the empirical cumulative density function $(c d f) G_{r}($.

$$
G_{r}(x)=\frac{1}{T} \sum_{t=1}^{T} 1_{\left(r_{t} \leq x\right)}
$$

Under the hypotheses:

$$
H_{0}: G(.)=F^{*}(x ; \theta) \text {; for all } x
$$

Versus

$$
H_{1}: G(.) \neq F^{*}(x ; \theta) \text {; for at least one } x
$$

With $\theta$ assumed to be known. However, when $\theta$ is unknown, Lilliefors test is used. According to Kolmogorov [43], the simplest measure of normality is the largest distance between the two functions $G_{r}(x)$ and $F^{*}(x ; \theta)$, which mathematically is expressed as

$$
K S=\sup _{\{x\}}\left|F^{*}(x ; \theta)-G(x)\right|
$$

Practically, this test is implemented as follows:

1) The data set is sorted in ascending order, with the new sample denoted as 
$\left\{\check{r}_{t}\right\}_{t=1}^{T}, \forall \check{r}_{1} \leq \check{r}_{2} \leq \cdots \leq \check{r}_{T}$; from which empirical cumulative density function $(c d f), G\left(\check{r}_{t}\right)=\frac{t}{T}$ is generated

2) We then generate the assumed $c d f F^{*}\left(\check{r}_{t} ; \theta\right)$ for every value of $\left\{\check{r}_{t}\right\}_{t=1}^{T}$. If the referenced distribution is normal, then we assume mean $\mu$ and standard deviation $\sigma$ are known

3) Finally, $K S$ test statistic is computed as: $K S=\sup _{\{t\}}\left|F^{*}\left(\check{r}_{t} ; \theta\right)-\left(\frac{t}{T}\right)\right|$

The major limitation of $K S$ however is that the mean and standard deviation are unknown, and have to be estimated from the sample, thereby leading to sampling errors. To adjust for this, the modified Lilliefors $K S_{L}$ test is applied.

\section{Lilliefors Test for Normality}

The Lilliefors test [44] tests the following null and alternative hypotheses for data sets up to $n$ (say, $n=1000$ )

$H_{0}$ : The data have been drawn from a normal distribution

$H_{1}$ : The data have been drawn from a non-normal distribution

Test Procedures

1) Compute the sample mean, $\bar{x}=\frac{1}{n} \sum_{i}^{n} x_{i}$ and the sample standard deviation,

$$
s=\sqrt{\frac{1}{n}} \sum_{i=1}^{n}\left(x_{i}-\bar{x}\right)^{2}
$$

2) Compute the normalized sample values $z_{i}$ as: $z_{i}=\frac{x_{i}-\bar{x}}{s}, \forall i=1,2, \cdots, n$ $(* *)$.

3) Compute the Lilliefors test statistic $T$ as follows: $T=\sup \left|F^{*}(x)-S(x)\right|$ where $T$ is the supremum over all $x$, of the absolute value of the difference $F^{*}(x)-S(x)$ and $F^{*}(x)$ is the cumulative distribution function of a normal distribution with mean zero (0) and standard deviation one (1); and $S(x)$ is the empirical distribution function of the values of $z_{i}$ computed using $\left(^{(*)}\right.$ above.

4) Reject $H_{0}$ and accept $H_{1}$ at the $\alpha$ significant level if $T$ exceeds the critical value for the test which can be obtained from Table A14 ${ }^{1}$ [44].

\subsection{Testing Dependency in Stock}

Time Dependence in Returns is very crucial in finance for the following reasons:

1) If the returns distribution is time dependent, then the statistical tests using unconditional statistics and inferences drawn from then could be misleading;

2) If time dependence can be fully exploited, one stands the better chance of making reliable forecasts of the level, volatility and higher moments of the re-

${ }^{1}$ Conover, W.J. 1999: Statistics of the Kolmogorov-Smirnov Type. Practical Nonparametric Statistics, $3^{\text {rd }}$ ed. Willey, N Y. 
turns.

Testing for Serial Correlation (Autocorrelation) in Returns

$$
H_{0}: \rho_{1}=\rho_{2}=\cdots=\rho_{p}=0
$$

Versus

$H_{1}$ : At least one $\rho_{i}$

$\rho_{i}$ is non-zero for the first p-lag auto-correlation. Where correlation $\left(\rho_{J}\right)$ of order $j$ is computed using the formula:

$$
\hat{\rho}_{j}=\frac{\sum_{t=j+1}^{T}\left(r_{t}-\bar{r}\right)\left(r_{t-j}-\bar{r}\right)}{\sum_{t=1}^{T}\left(r_{t}-\bar{r}\right)^{2}}, \quad \forall 0 \leq j<T-1
$$

The appropriate test statistic subject to $H_{0}$ is Ljung-Box $(Q)$ statistic, given as:

$$
Q_{p}=T(T+2) \sum_{j=1}^{p} \frac{1}{T-j} \hat{\rho}_{j}^{2} \approx \chi_{p}^{2} \text { under } H_{0} .
$$

\section{Testing for Serial Correlation in Volatility}

To test for existence of time dependence in volatility requires obtaining a time-varying measure of volatility. The two possible measures here are: 1) use of mean-adjusted squared returns or 2) use of absolute returns.

\section{Assumptions}

$$
\begin{gathered}
r_{t}=\mu+\epsilon_{t} \\
\varepsilon_{t}=\sigma_{t} z_{t}
\end{gathered}
$$

where $\mu$, is the constant mean, $\varepsilon_{t}$ is the mean adjusted returns, $\sigma_{t}$ represents the time varying volatility and $Z_{t} \sim N(0,1)$ innovation. Given the information set, $F_{t-1}$ at time, $t-1$, the expected value of the squared residuals is given as:

$$
E\left[\varepsilon_{t}^{2} \mid F_{t-1}\right]=\sigma_{t}^{2} E\left[z_{t}^{2} \mid F_{t-1}\right]=\sigma_{t}^{2}
$$

With, $z_{t}^{2} \sim \chi_{(1)}^{2}$. Hence, $\varepsilon_{t}^{2}$, can be viewed as proxy for the volatility at time $t$. Alternatively, omitting $\mu$ for the moment, we have that, $r_{t} \sim N\left(0, \sigma_{t}^{2}\right)$.

\section{Results and Discussion}

This section presents some results of the analyses carried out in this research. We divide the presentation into three aspects, namely preliminary results on exploratory data analyses, quantitative results, and implications for theory and practice.

\subsection{Preliminary Results: Exploratory Data Analysis}

In this section we present exploratory results in terms of graphs, for instance, Figures 1-8 contain both daily price and return series for the four banks. For First bank (Figure 1 and Figure 2), there was substantially high volatility noted around September 2003 as well as June, 2004 due to sharp drops in the stock prices, which was big enough to have caused relatively high spikes in 


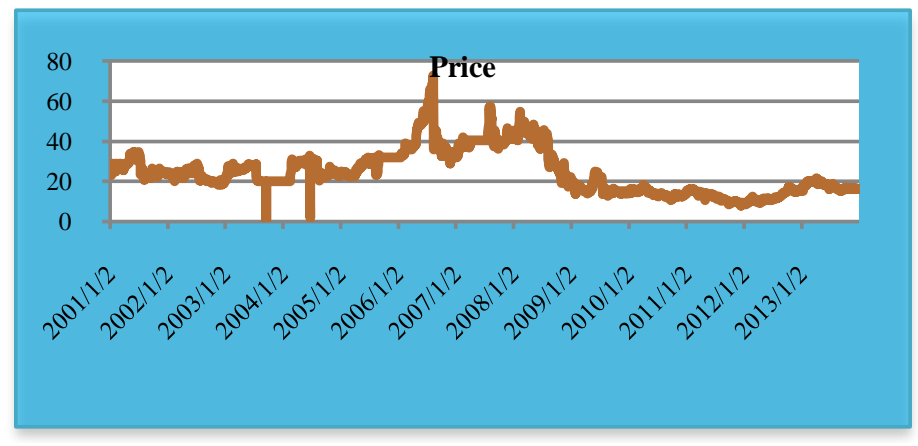

Figure 1. First bank price series: 2/1/2001-31/12/2013.

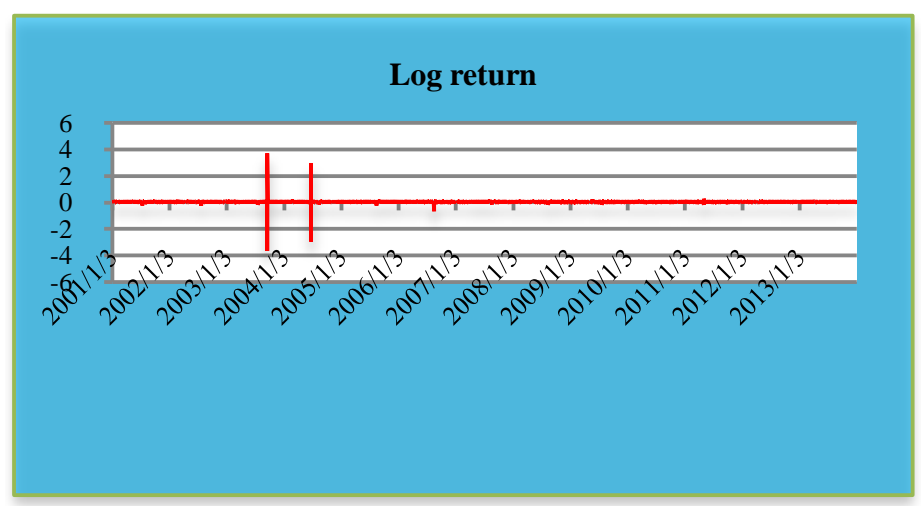

Figure 2. First bank return series: 2/1/2001-31/12/2013.

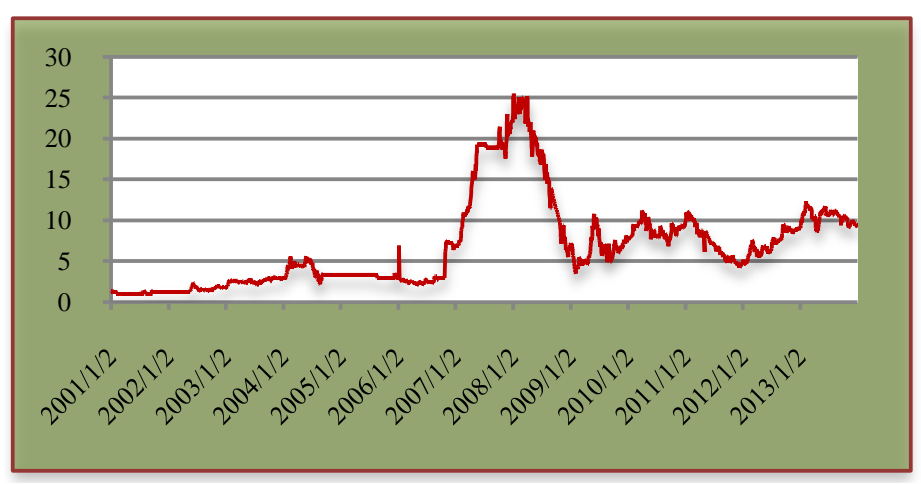

Figure 3. Access bank price series: 2/1/2001-31/12/2013.

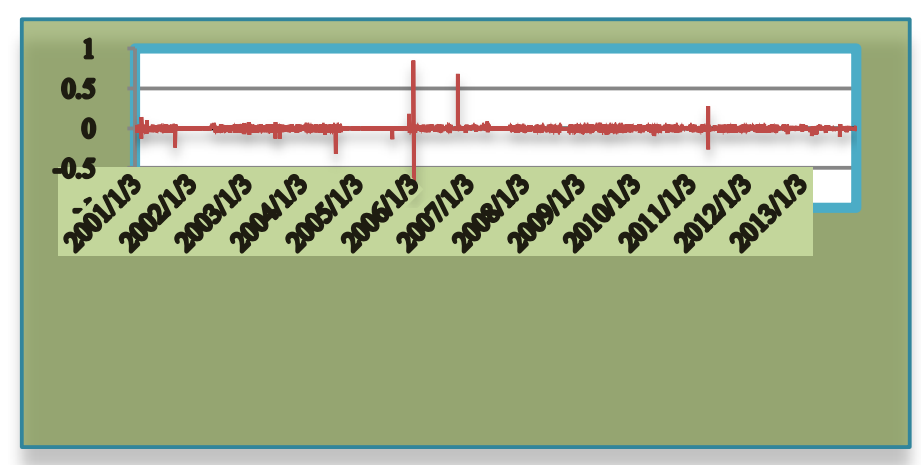

Figure 4. Access bank log return series: 3/1/2001-31/12/2013. 


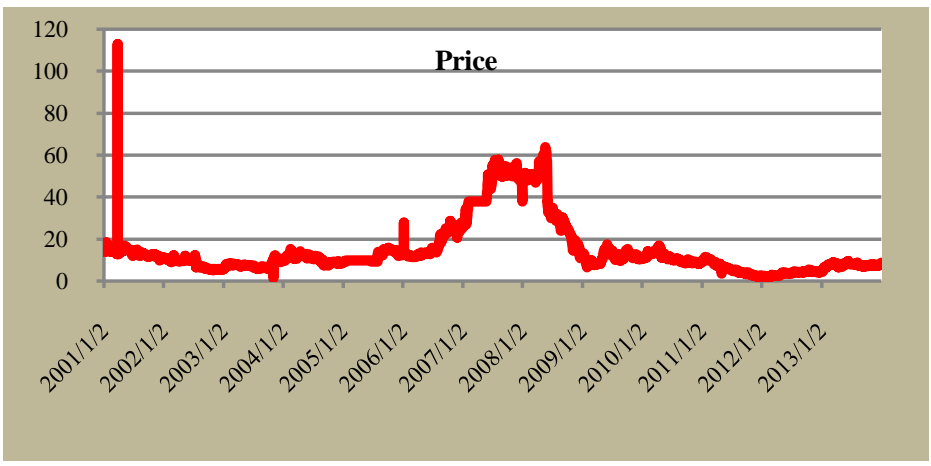

Figure 5. UBA price series: 2/1/2001-31/12/2013.

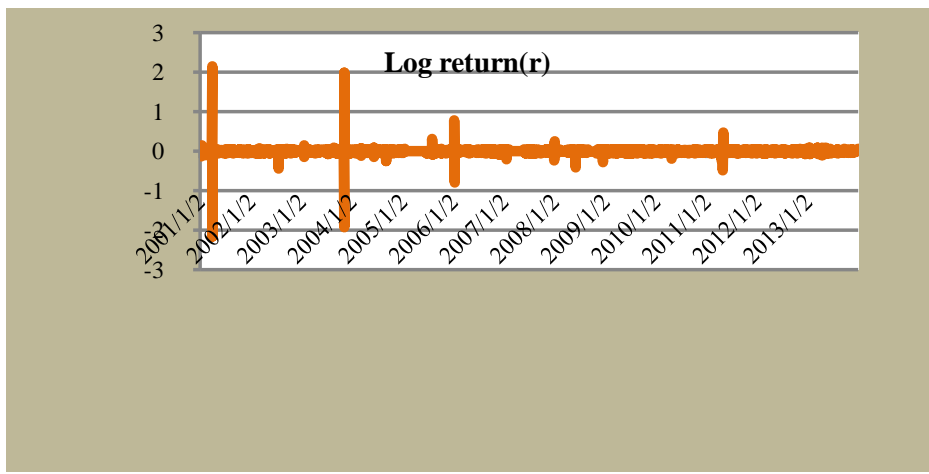

Figure 6. UBA return series: 2/1/2013-31/12/2013.

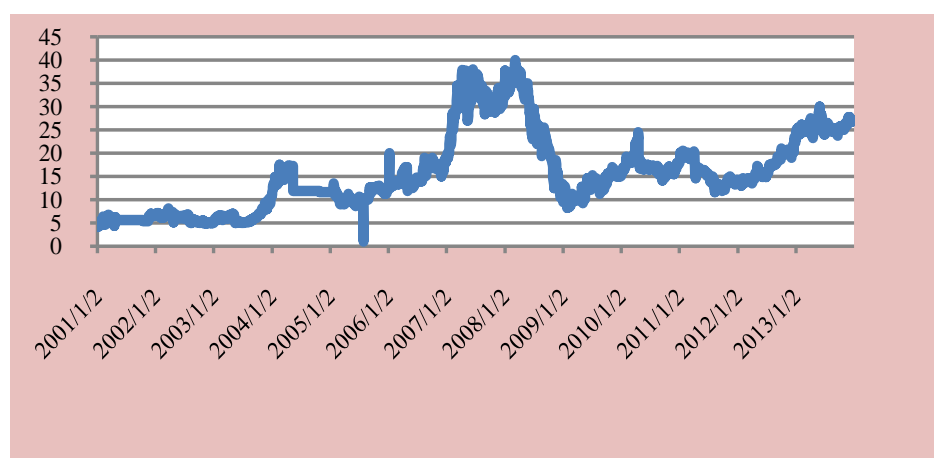

Figure 7. Guaranty trust bank price series: 2/1/2001-31/12/2013.

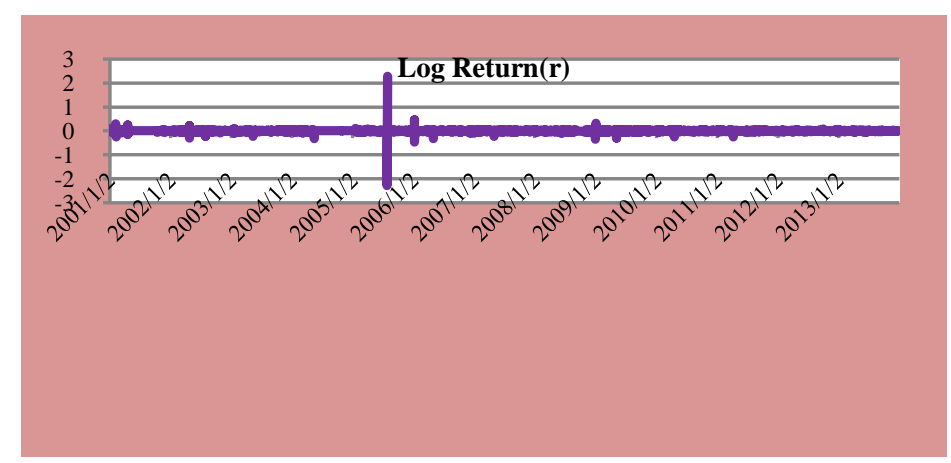

Figure 8. Guaranty trust bank return series: 2/1/2001-31/12/2013. 
the returns volatility. Though there was significant rise in price recorded around February, 2006, there was no relative effect on the volatility level for the bank. These contrasting effects of both drop and rise in price level on the returns volatility may be likened to the asymmetric behaviour of the returns widely established in most researches as an important stylized fact. Apart from the two periods one could see that there is relatively low spikes level in the returns volatility across the years.

For Access bank (Figure 3 and Figure 4), January and October 2006, high spikes are observed in the return series which could be traced to the periods preceding gradual rise in the stock prices. Like in the case of First bank, the increase in stock price recorded for Access bank around February, 2008 does not yield commensurate level of fluctuations in the return series as do the drop in price (for instance, 2011 drop in price). The situation is however slightly different with UBA where around 2001 a noticeable rise in price level gives rise to the first spike in the return series. Also, the first sudden increase in price observed around June, 2007 suffered a slight drop around December, 2007 before the price rises to the pick sometimes in April, 2008.

For Guaranty bank, the only noticeable spike in the return series is attributable to the sharp decline in the stock price around July, 2005. Also for this bank, the first sharp increase in price experienced between March and April, 2007 showed a gradual decline from around May to August, 2007 before picking again to reach its pick in January, 2008. In all, no peculiar trend could be traced to the price series, indicating non stationarity.

However, in general, it could be deduced that the extent of fluctuations in the prices for the four banks is not satisfactorily and commensurately reflected in the return series, which to us might be attributable to: 1) such jumps or (swings) in price series not being high enough to cause proportionate effects on the returns volatility; or 2) the time horizon being relatively too long to have reflected such level of jumps. Hence, we choose to partition the time into four sub-periods based on the series of scenarios witnessed by the banking sector of Nigerian economy within the referenced periods. The four periods considered are: 1) Before recapitalization/banking merger (January, 2001-May, 2004); 2) Soludo's regime (June, 2004-May, 2009) -initiator of the first banks recapitalization; 3) Sanusi's regime (June, 2009-December, 2013), including second phase of banking reforms; and; 4) Periods of global financial crises (January, 2007-December, 2008).

\section{Pre-Capitalization/ Banking merger}

Figures 9-16 present both price and price return series for the four banks from Jan, 2001 to May, 2004. It is noticed that while the fluctuations in the price series appear more pronounced, the return series appear similar as it was when the longer length of time was used. For Access bank the spikes in both price and return series that appear relatively flattened in the longer horizon become well pronounced. The price experiences gradual rise from around May, 2002 reaches 


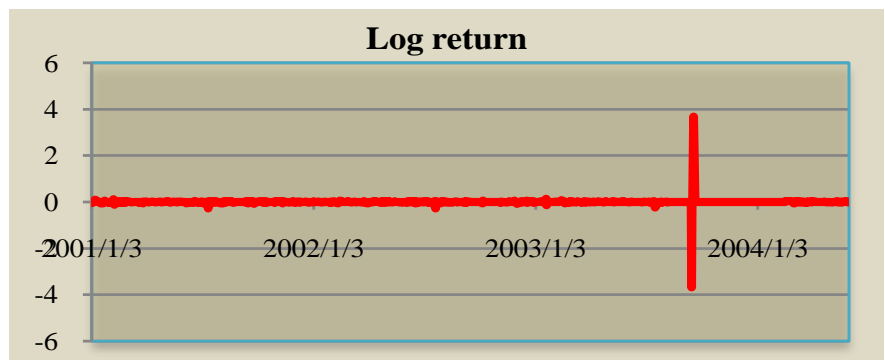

Figure 9. First bank return series: 3/1/2001-30/5/2004.

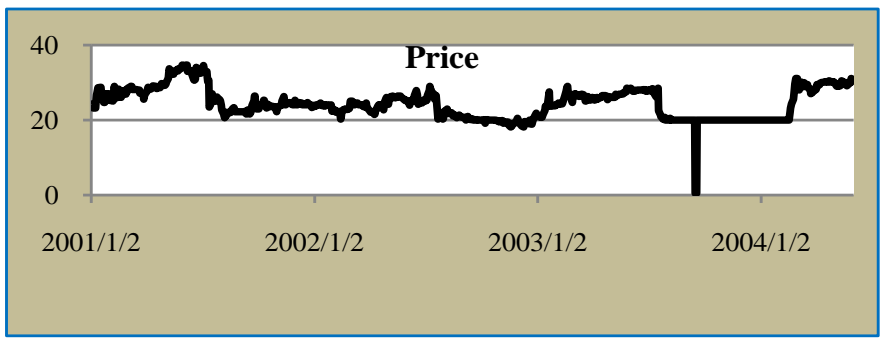

Figure 10. First bank price series: 3/1/2001-30/5/2004.

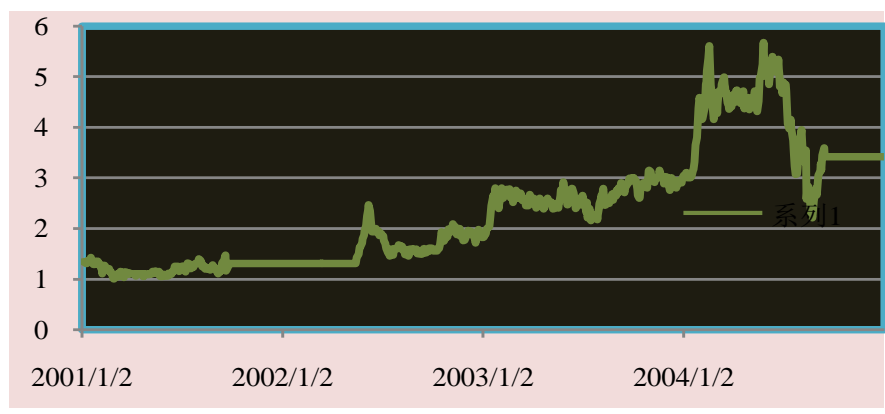

Figure 11. Access bank price series: 2/1/2001-30/12/2004.

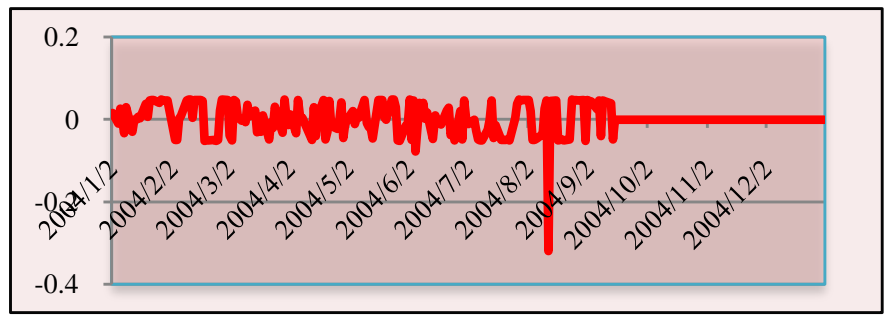

Figure 12. Access bank returns series: 3/1/2004-31/12/2004.

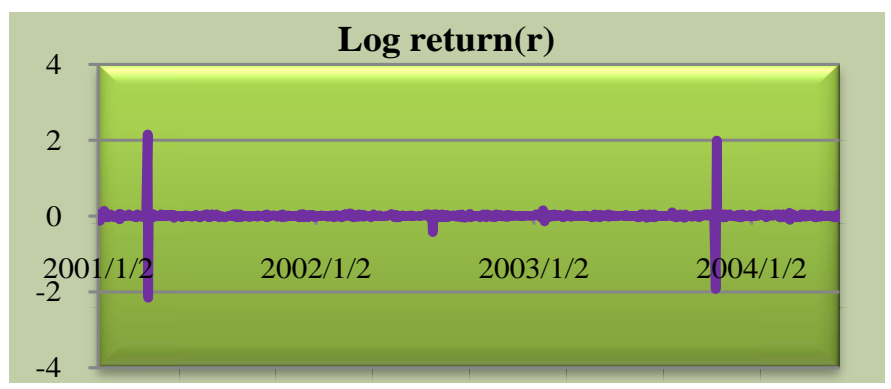

Figure 13. UBA returns series: 3/1/2004-31/12/2004. 


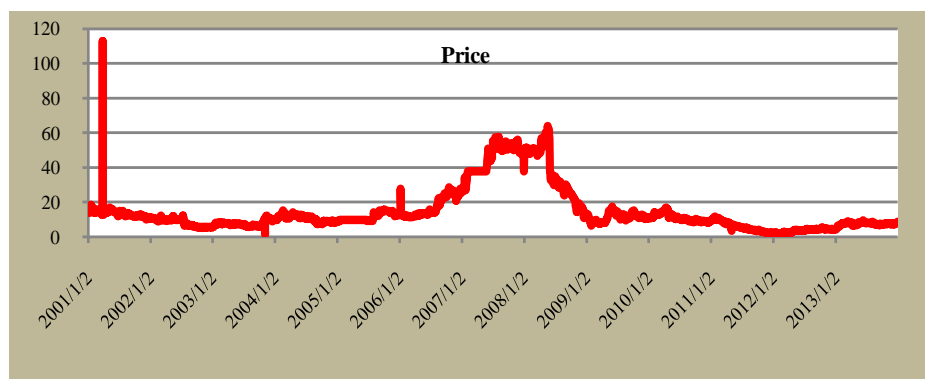

Figure 14. UBA price series: 3/1/2004-31/12/2004.

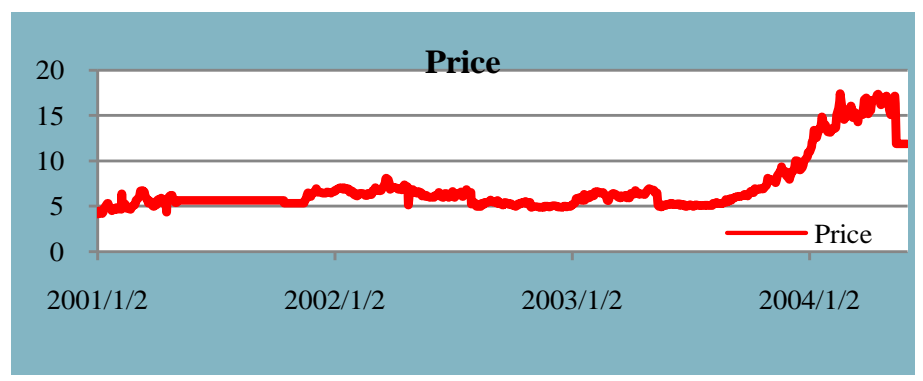

Figure 15. Guaranty trust bank price series: 2/1/2001-31/5/2004.

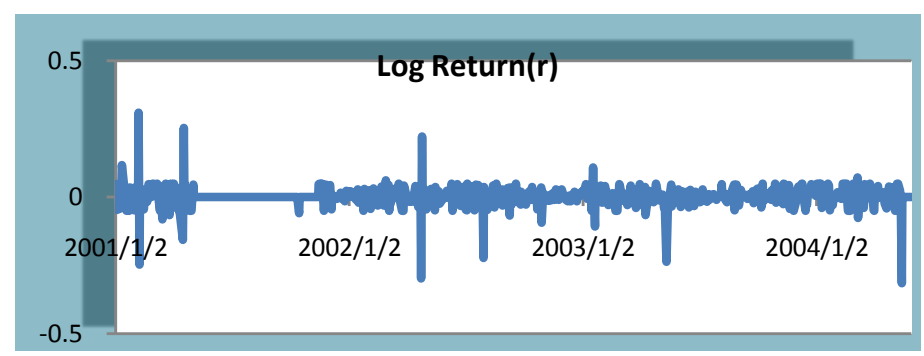

Figure 16. Guaranty trust banks' return series: 2/1/2001-31/5/2004.

an altitude in around February, 2004, drops slightly around March, and then picks up again to reach its peak around May, 2005. After this time, there was a sharp decline in the stock price due to possibly a deep shock in around August, 2004. The returns on the other hand appear substantially clustered right from 2001 till around August, 2004 when a deeper and pronounced spike sets in due to the sharp drop in the price level around this time.

For UBA, both price and return series appear to maintain same pattern as they were in the longer horizon. For example, two deep spikes in the return series around March, 2001 and November, 2003 are observed. For Guaranty Trust bank, about seven sharp and pronounced jumps in the return series which were not glaringly accounted for in the longer time series are noted between 2001 and 2004. The periods are Feb., 2001; April, 2001; April, 2002; July, 2002; January, 2003; May, 2003 and May, 2004. Outside these periods one could see that the returns are highly clustered. In summary, it appears that the shorter the time horizon, the more pronounced the fluctuation level in the price series is captured or reflected in the return series. 


\section{Bank re-capitalization/merger (2004-2009)}

More variations and clusters are becoming pronounced across all the banks, except for First bank which tends to maintain its initial pattern; see Figures 17-24 for the detail.

Global financial crises periods (January 2007-December, 2008)

Figures 25-32 contain both the price and return series from January, 2007 to December, 2008. It could be ascertained that virtually all the four banks have records of thick, clustered and well pronounced volatility. For instance, considering Guaranty bank, the volatility rate in the return series is highly pronounced with a very big spike observed around May, 2007. First bank has two big and sharp volatility levels around August, 2007 and August, 2008, with other periods having thick and clustered volatility except for the periods between April-July, 2007 as well as August-October, 2008, which could be regarded as the periods of calmness or stable fluctuations. Access bank witnesses high volatility throughout these periods except for periods falling between May-September, 2007 with minimal or stable fluctuations in the series. UBA on the other hand has the records of three big volatility levels around December, 2007; June, 2008 and December, 2008; with the remainder of the periods witnessing highly clustered series

\section{Periods of Second Banking Reforms (2009-2013)}

Figures 33-40 contain both the price and return series for the four banks. These periods represent periods of intense volatility. That is periods when the returns are highly clustered together. More jumps or spikes are noticed around most of these series. For example, First bank records four pronounced jumps noticed around July, 2009; May, 2010; May, 2011 as well as January, 2013. The returns for this bank could be said to be noisy. Access bank experiences biggest jump around May, 2011, with the rest of the periods having thick and highly clustered returns. Guaranty Trust bank witnesses pronounced spikes around April, 2010; April, 2011 and October, 2012. Lastly, UBA though records serious spike around May, 2011, the rest of these periods are characterized by intense and high volatility level.

In general, from these results it could be deduced that uncommon events and or reforms in the banking sector often affect the returns volatility. With these findings, one could say that there is significant level of dependence or serial auto-correlation in the returns of these banks. However, findings based on this exploratory approach are not always full reflection of the reality; it provides a pictorial reflection which requires further confirmatory statistical tests.

\section{Normality Test Results}

In this section the normality plots for both returns and mean-adjusted returns, as well as the q-plots for each of the banks are presented. While Figures A1-A4 (see Appendix A) present the normal plots with superimposed distributions, Figures B1-B4 (see Appendix B) have normal Q-Q plots for the four banks. From the plot it could be observed that virtually all the graphs display highly 


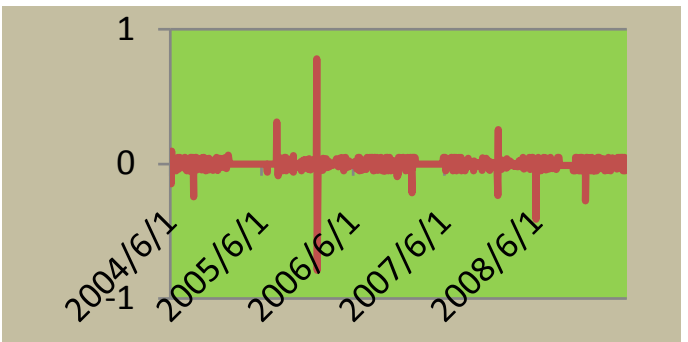

Figure 17. UBA return series: 1/6/2004-28/5/2009.

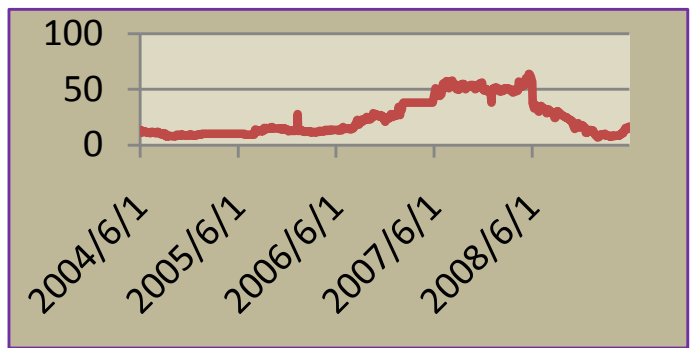

Figure 18. UBA price series: 1/6/2004-28/5/2009.

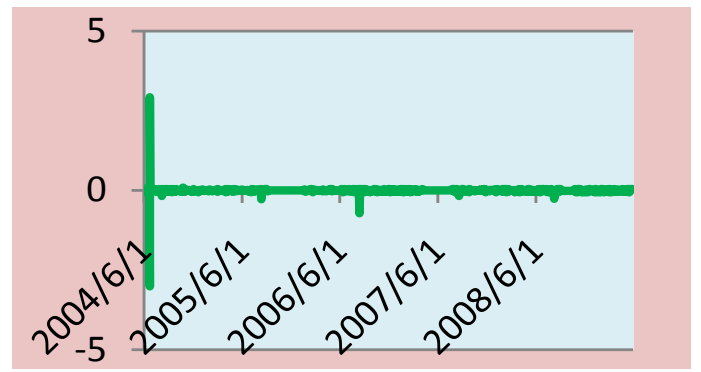

Figure 19. First bank return series: 1/6/2004-28/5/2009.

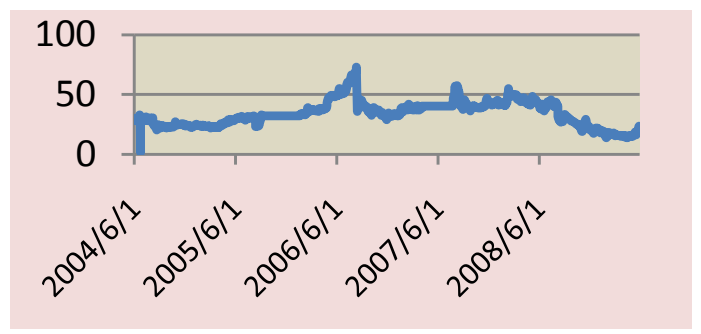

Figure 20. First bank price series: 1/6/2004-28/5/2009.

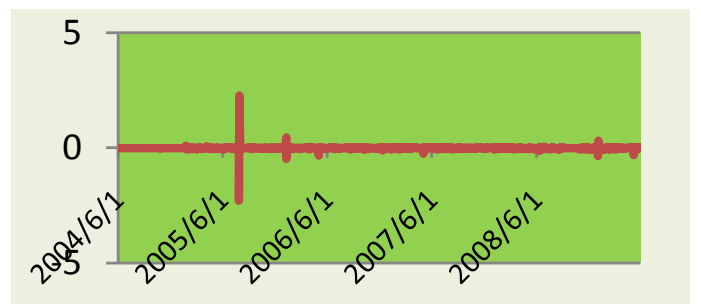

Figure 21. Guaranty trust bank return series: $1 / 6 / 2004-28 / 5 / 2009$. 


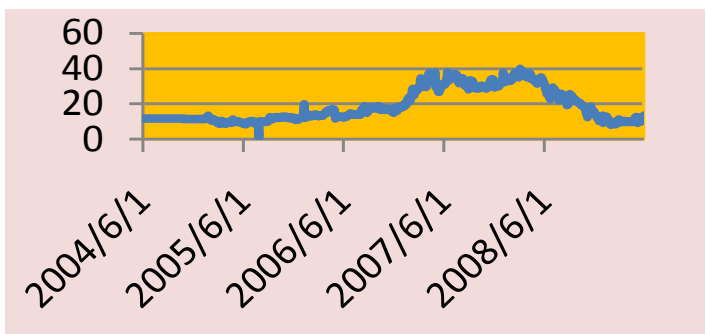

Figure 22. Guaranty trust bank price series: 1/6/2004-28/5/2009.

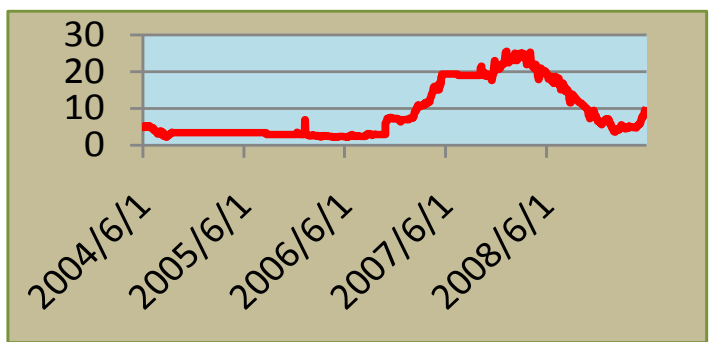

Figure 23. Access bank price series: 1/6/2004-28/5/2009.

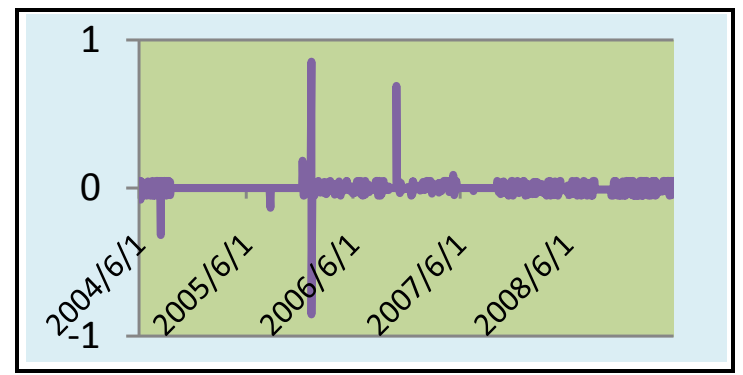

Figure 24. Access bank return series: 1/6/2004-28/5/2009.

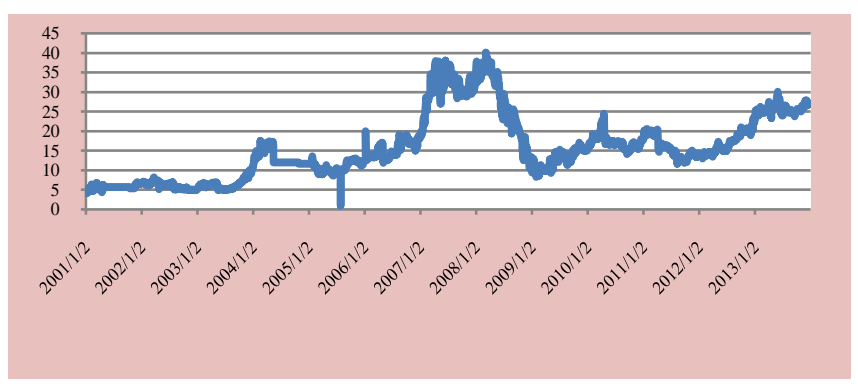

Figure 25. Guaranty trust bank price series: 4/1/2007-31/12/2008.

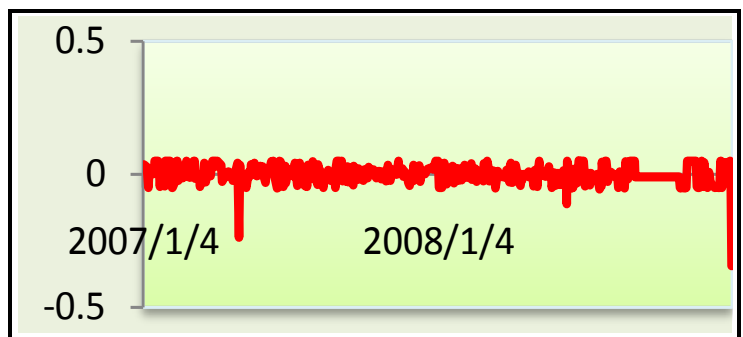

Figure 26. Guaranty trust bank return series: 4/1/2007-31/12/2008. 


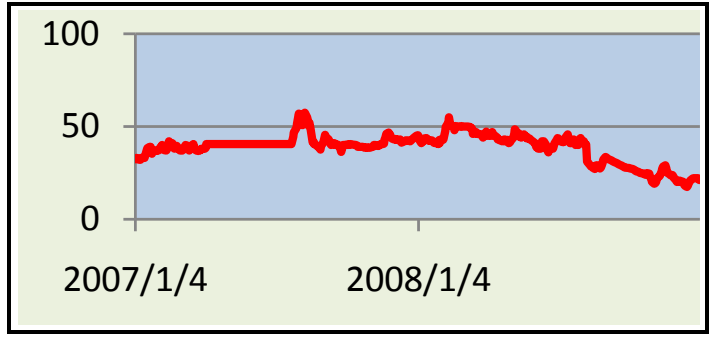

Figure 27. First bank price series: 4/1/2007-31/12/2008.

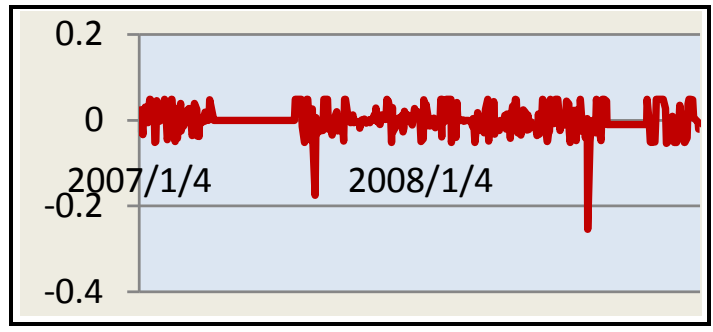

Figure 28. First bank return series: 4/1/2007-31/12/2008.

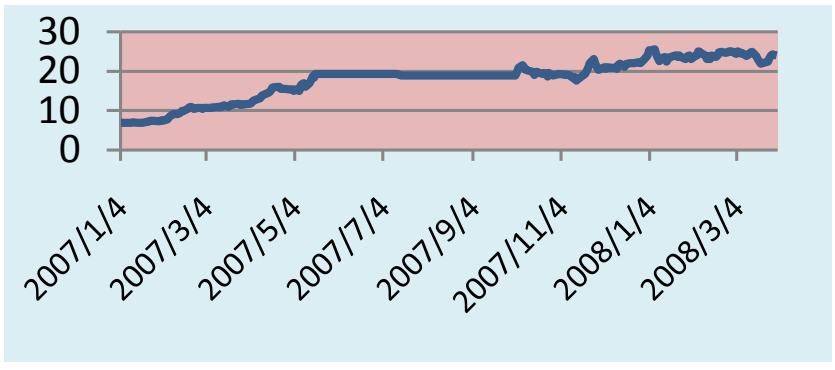

Figure 29. Access bank price series: 4/1/2007-31/12/2008.

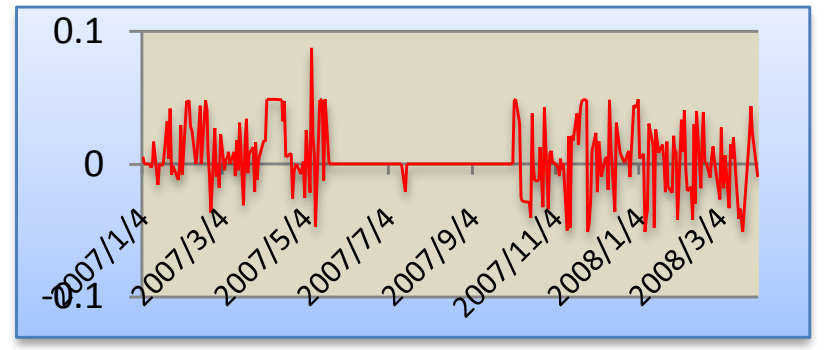

Figure 30. Access bank return series: 4/1/2007-31/12/2008.

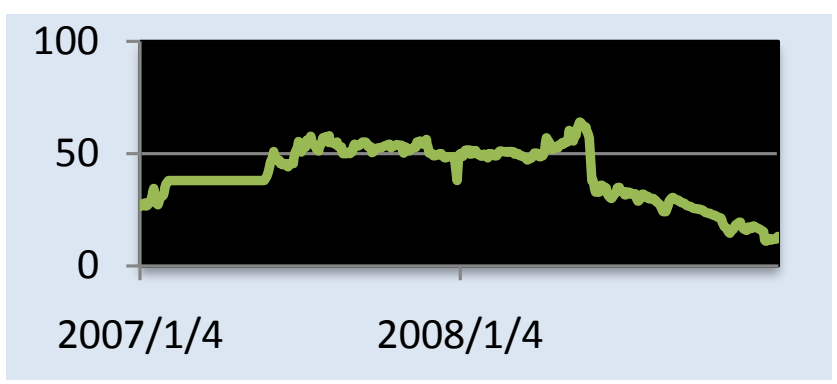

Figure 31. UBA price series: 4/1/2007-31/12/2008. 


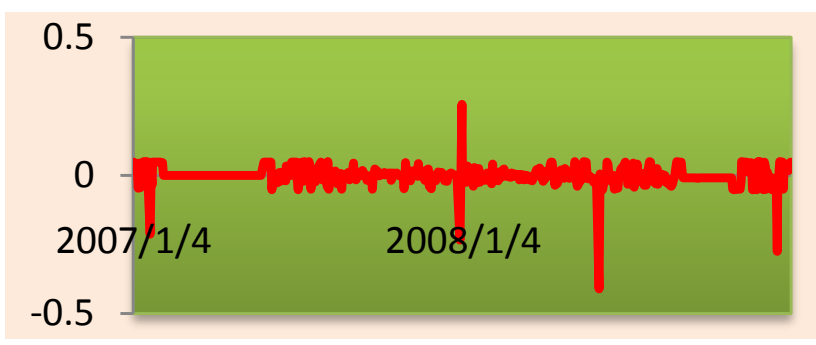

Figure 32. UBA return series: 4/1/2007-31/12/2008.

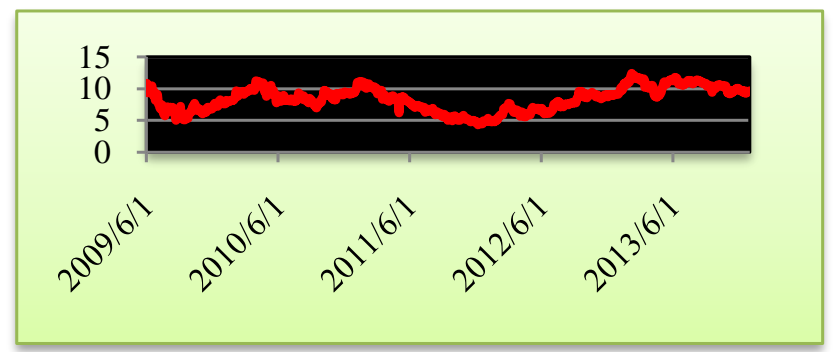

Figure 33. Access bank price series: 1/6/2009-31/12/2013.

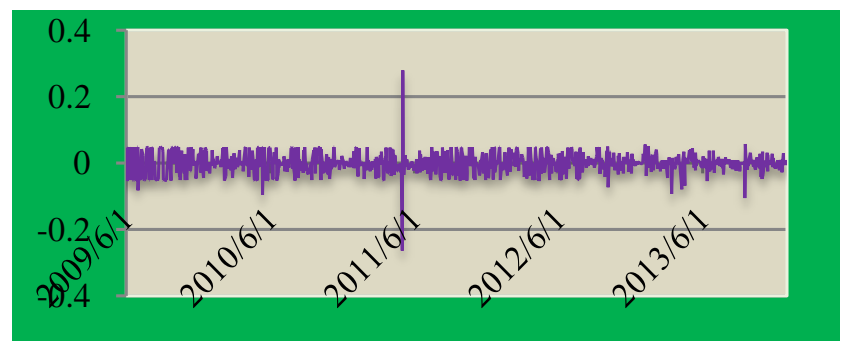

Figure 34. Access bank return series: 1/6/2009-31/12/2013.

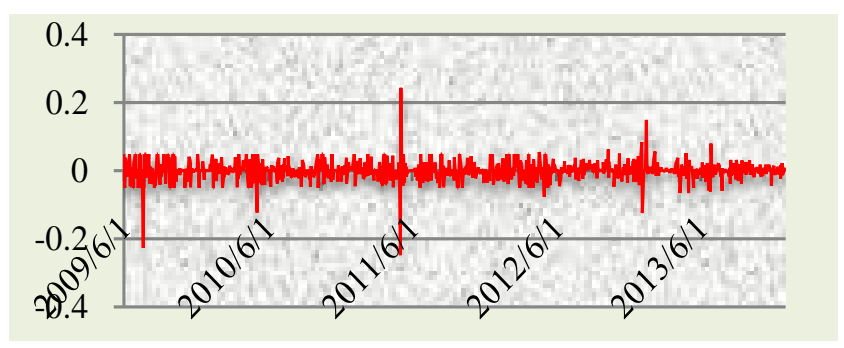

Figure 35. First bank return series: 1/6/2009-31/12/2013.

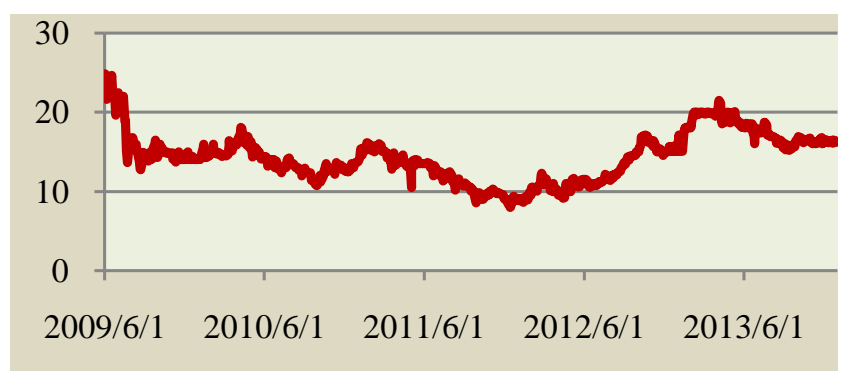

Figure 36. First bank price series: 1/6/2009-31/12/2013. 


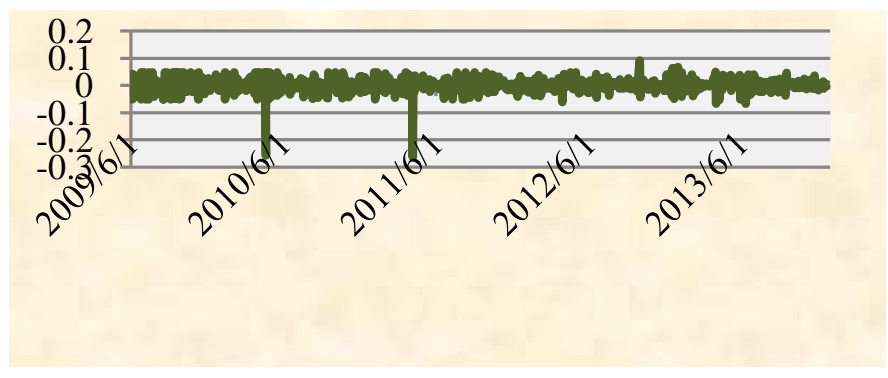

Figure 37. Guaranty trust bank return series: 1/6/2009-31/12/2013.

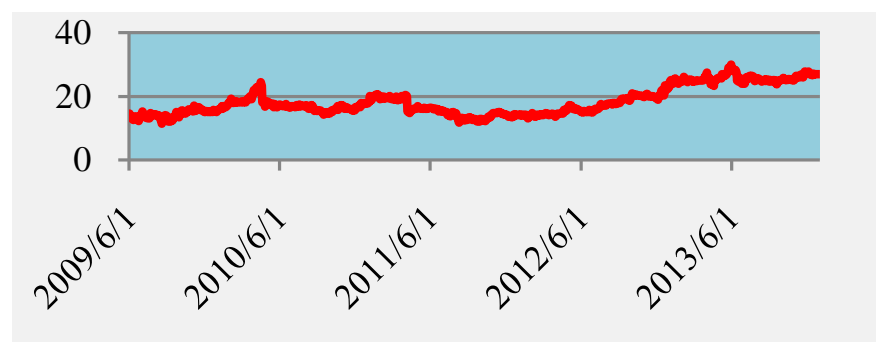

Figure 38. Guaranty trust bank price series: 1/6/2009-31/12/2013.

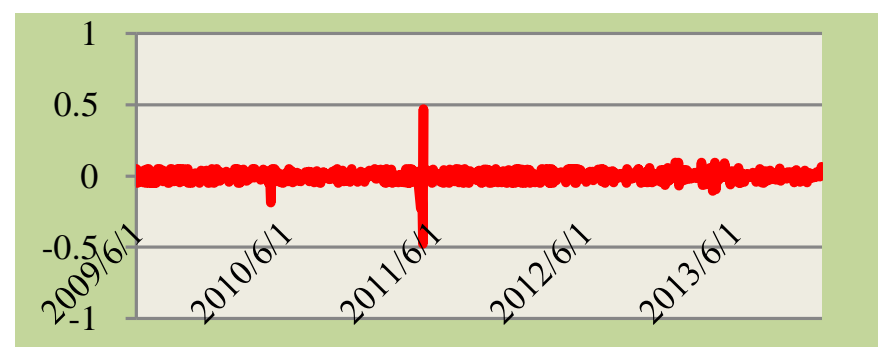

Figure 39. UBA return series: 1/6/2009-31/12/2013.

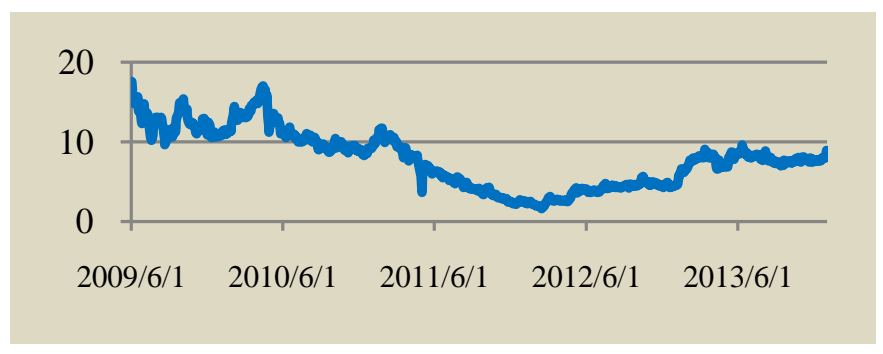

Figure 40. UBA price series: 1/6/2009-31/12/2013.

peak (leptokurtic) distributions, with approximately symmetric shapes but fat tails, except for Guaranty bank whose return is rightly skewed. These findings are in line with Taylor (2011)'s result as well as many other researchers on the distribution of daily stock returns, especially for frequently traded stocks. Confirming the non-normality of the returns, the q-plots reflect non-normality since most of the points in each case fall far away from the straight line. Thus, one could to some extent say that daily returns exhibit non-normality. 


\section{Exploring Dependence in Returns and Volatility}

Figures C1-C6 (see Appendix C) explore the extent of serial auto correlation in returns and in volatility. The plots have auto-correlations for daily returns, absolute returns and mean-adjusted returns for each of the banks. While that of daily returns is to ascertain how auto-correlated each return series is, those of absolute and mean-adjusted returns determine the extent of dependence in volatility. For the four banks, while auto-correlations for both absolute and mean-adjusted returns are positive for substantial number of lags, those of the returns exhibit negative or near zero autocorrelations. It could also be noticed that Access bank has positive auto-correlation in absolute returns for several lags and at the same time the positive correlations persist and refuse to die off for many lags, indicating the probability of the returns for this bank to have long memory; which is another very important stylized fact. The presence of significant positive autocorrelation in absolute returns is also a sign of existence of volatility clustering and persistence in the returns for these banks. These findings, as reported by many researchers across different markets, for various stock returns, note that the ACF of absolute (or squared) returns remains positive and decays slowly over several lags. This feature is known to be due to the autoregressive conditional heteroscedasticity (ARCH) effect which characterises stock returns [45].

\subsection{Quantitative Results}

In this section the outcomes of the following confirmatory statistical tests are presented: 1) Normality tests based on moments and those based on density function of the distribution; and 2) dependence tests, either in returns or in volatility.

\section{Normality test}

\section{Testing for normality in the returns using moments}

We use Jarque-Bera statistic joint test built around skewness and kurtosis as well as Doornik and Hansel statistic. Table 5 and Table 6 contain the summary statistics and the relevant test statistics. Specifically, from Table 6, we find that while the two other banks have skewness not significantly different from zero, Access and Guaranty trust banks are significantly skewed, with GTB having the highest skewness. Looking at the mean returns of the four banks, one would say that they are approximately equal to zero, which is in line with the standard Random Walk assumption. Another notable observation here is that GTB with relatively highest variance produces the highest mean; this is another important feature of short term stock returns behaviour. Also, First bank with negative skewness is prone to effects of a negative shock than a positive shock compared to others which are likely to be influenced by good news than negative news. And finally, compared to other banks, GTB with the highest coefficients of skewness and kurtosis would seem to be excessively favoured by good news for prolonged periods within the considered periods. 
Table 5. Summary statistics/moments.

\begin{tabular}{cccccccccc}
\hline Banks & Min & Max & Median & Mean & Interquartile & Std. Dev. & Variance & T \\
\hline Access & -0.85398 & 0.85399 & 0.00 & 0.000599 & 0.0224 & 0.03795 & 0.001 & 3201 \\
First & -3.6889 & 3.6889 & 0.00 & -0.00012 & 0.020792 & 0.12238 & 0.015 & 3200 \\
Guaranty & -0.8980 & 8.8039 & 0.00 & 0.003589 & 0.021614 & 0.15974 & 0.026 & 3203 \\
UBA & -2.1654 & 2.1538 & 0.00 & -0.00015 & 0.0308 & 0.08319 & 0.007 & 3202 \\
\hline
\end{tabular}

Table 6. Normality tests.

\begin{tabular}{ccccc}
\hline Banks & Skewness & Kurtosis & Jarque-Bera $(J B)$ & Doornik-Hansen $(\tilde{W})$ \\
\hline Access & 1.597 & 196.323 & $4,986,026.543$ & $70,564.67$ \\
First & -0.434 & 732.664 & $70,988,040.94$ & $190,699.3472$ \\
Guaranty Trust & 52.203 & 2879.581 & $1,105,784,884$ & $6,333,537.372$ \\
UBA & 0.192 & 481.552 & $30,554,040.4$ & 27.2387 \\
\hline
\end{tabular}

However, the four banks have excess kurtosis far above " 3 ", the benchmark for a normal distribution. Further, the results from "JB" and "DH" tests reveal that the returns for these banks cannot be described by a normal distribution. The excess kurtosis observed in the returns of the four banks might be traced to the presence of conditional heteroscedasticity that is, time varying nature of the volatility (same view shared by Corhay and Tourani) [46].

\section{Using Distributional Approach}

Table 7 contains the details on Kolmogorov-Smirnov (KS), according to the $p$-value (0.000), it could be deduced that none of the banks return series is distributed normally.

\section{Determining Dependencies in Returns and Volatility \\ Dependency in Returns}

This is achieved by computing and determining the significance of serial autocorrelation in daily returns using Box Ljung $(Q)$ statistic. Tables 8-11 contain the results of the computations as well as the $p$-values for Access, UBA, First and Guaranty Trust bank respectively. It could be observed that though all the auto-correlation functions for the four banks are significant at first lag up till 16th lag, all remain negatives at least at lag 1 across the four banks; this according to most researches is an important stylized fact of daily stock returns (see [33] [47]). Meanwhile the significant level of ACF for the four banks at lag 1 is a sign of persistence or long term dependence in their returns.

\section{Dependency in Volatility}

Tables 12-15 contain the outcome of the serial dependence in absolute returns for Guaranty, First bank, Access bank and UBA respectively, as a measure of dependence in volatility. It is found that all the autocorrelation functions for the four banks are significant at 5\% level of significance and all positives at lag 1 . This is a confirmation of the presence of long term dependence in absolute 
Table 7. Tests of normality.

\begin{tabular}{cccc}
\hline Banks & df & Statistic (KS) & $p$-value \\
\hline First & 3199 & 0.338 & 0.000 \\
Access & 3202 & 0.140 & 0.000 \\
Guaranty Trust & 3203 & 0.380 & 0.000 \\
UBA & 3202 & 0.268 & 0.000 \\
\hline
\end{tabular}

Table 8. Auto-correlation for ACCESS BANK.

\begin{tabular}{|c|c|c|c|c|c|c|c|c|c|c|c|c|c|c|c|c|}
\hline Lag & 1 & 2 & 3 & 4 & 5 & 6 & 7 & 8 & 9 & 10 & 11 & 12 & 13 & 14 & 15 & 16 \\
\hline $\begin{array}{c}\text { Auto- } \\
\text { correlation }\end{array}$ & -0.09 & 0.038 & -0.013 & 0.013 & -0.005 & 0.018 & -0.034 & -0.005 & 0.005 & 0.018 & -0.008 & 0.013 & -0.021 & -0.017 & -0.012 & 0.007 \\
\hline $\mathrm{df}$ & 1 & 2 & 3 & 4 & 5 & 6 & 7 & 8 & 9 & 10 & 11 & 12 & 13 & 14 & 15 & 16 \\
\hline $\begin{array}{l}\text { Standard } \\
\text { Error }\end{array}$ & 0.018 & 0.018 & 0.018 & 0.018 & 0.018 & 0.018 & 0.018 & 0.018 & 0.018 & 0.018 & 0.018 & 0.018 & 0.018 & 0.018 & 0.018 & 0.018 \\
\hline $\begin{array}{l}\text { Box- } \\
\text { Ljung }\end{array}$ & 23.3 & 27.78 & 28.33 & 28.85 & 28.94 & 30.00 & 33.72 & 33.81 & 33.88 & 34.9 & 35.07 & 35.58 & 36.98 & 37.87 & 38.322 & 38.484 \\
\hline$p$-value & 0.00 & 0.00 & 0.00 & 0.00 & 0.00 & 0.00 & 0.00 & 0.00 & 0.0 & 0.00 & 0.00 & 0.00 & 0.00 & 0.00 & 0.00 & 0.00 \\
\hline
\end{tabular}

Table 9. Auto-correlation for UBA.

\begin{tabular}{|c|c|c|c|c|c|c|c|c|c|c|c|c|c|c|c|c|}
\hline Lag & 1 & 2 & 3 & 4 & 5 & 6 & 7 & 8 & 9 & 10 & 11 & 12 & 13 & 14 & 15 & 16 \\
\hline $\begin{array}{c}\text { Auto- } \\
\text { correlation }\end{array}$ & -0.085 & 0.038 & -0.013 & 0.013 & -0.005 & 0.018 & -0.034 & -0.005 & 0.005 & 0.018 & -0.008 & 0.013 & -0.021 & -0.017 & -0.012 & 0.007 \\
\hline df & 1 & 2 & 3 & 4 & 5 & 6 & 7 & 8 & 9 & 10 & 11 & 12 & 13 & 14 & 15 & 16 \\
\hline Std Error & 0.018 & 0.018 & 0.018 & 0.018 & 0.018 & 0.018 & 0.018 & 0.018 & 0.018 & 0.018 & 0.018 & 0.018 & 0.018 & 0.018 & 0.018 & 0.018 \\
\hline $\begin{array}{c}\text { Box- } \\
\text { Ljunnk }\end{array}$ & 23.13 & 27.78 & 28.33 & 28.85 & 28.94 & 30.00 & 33.72 & 33.81 & 34.88 & 34.88 & 35.07 & 35.58 & 36.99 & 37.87 & 38.32 & 38.48 \\
\hline$p$-value & 0.00 & 0.00 & 0.00 & 0.00 & 0.00 & 0.00 & 0.00 & 0.00 & 0.00 & 0.00 & 0.00 & 0.00 & 0.00 & 0.001 & 0.001 & 0.001 \\
\hline
\end{tabular}

Table 10. Auto-correlation for first BANK.

\begin{tabular}{|c|c|c|c|c|c|c|c|c|c|c|c|c|c|c|c|c|}
\hline Lag & 1 & 2 & 3 & 4 & 5 & 6 & 7 & 8 & 9 & 10 & 11 & 12 & 13 & 14 & 15 & 16 \\
\hline $\mathrm{ACF}$ & -0.182 & 0.001 & -0.294 & -0.005 & 0.004 & 0.000 & -0.001 & -0.003 & 0.001 & 00.004 & -0.004 & 0.005 & -0.008 & 0.002 & 0.001 & -0.002 \\
\hline STDER & 0.018 & 0.018 & 0.018 & 0.018 & 0.018 & 0.018 & 0.018 & 0.018 & 0.018 & 0.018 & 0.018 & 0.018 & 0.018 & 0.018 & 0.018 & 0.018 \\
\hline Q-Statistic & 105.5 & 105.5 & 381.7 & 381.8 & 381.9 & 381.9 & 381.9 & 381.9 & 381.91 & 381.95 & 382.0 & 382.09 & 382.30 & 382.31 & 382.31 & 382.32 \\
\hline $\mathrm{df1}$ & 1 & 2 & 3 & 4 & 5 & 6 & 7 & 8 & 9 & 10 & 11 & 12 & 13 & 14 & 15 & 16 \\
\hline$p$-value & 0.00 & 0.00 & 0.00 & 0.00 & 0.00 & 0.00 & 0.00 & 0.00 & 0.00 & 0.00 & 0.00 & 0.00 & 0.00 & 0.00 & 0.00 & 0.00 \\
\hline
\end{tabular}

returns; hence dependence in volatility. Also observed is that while all autocorrelation functions (ACF) for Access and Guaranty Trust banks are all positive from lag one through to lag 16, UBA has a negative ACF at lag 16, First bank has negative ACFs at lags 6, 7, 8, 9,10,14, 15, and 16 . 
Table 11. Auto-correlation for guaranty trust BANK.

\begin{tabular}{|c|c|c|c|c|c|c|c|c|c|c|c|c|c|c|c|c|}
\hline Lags & 1 & 2 & 3 & 4 & 5 & 6 & 7 & 8 & 9 & 10 & 11 & 12 & 13 & 14 & 15 & 16 \\
\hline $\mathrm{ACF}$ & -0.099 & -0.001 & -0.001 & 00.00 & -0.003 & -0.002 & -0.003 & 0.002 & 0.000 & 0.001 & 0.002 & 0.001 & -0.004 & -0.004 & -0.004 & -0.004 \\
\hline STDERR & 0.018 & 0.018 & 0.018 & 0.018 & 0.018 & 0.018 & 0.018 & 0.018 & 0.018 & 0.018 & 0.018 & 0.018 & 0.018 & 0.018 & 0.018 & 0.018 \\
\hline $\mathrm{df}$ & 1 & 2 & 3 & 4 & 5 & 6 & 7 & 8 & 9 & 10 & 11 & 12 & 13 & 14 & 15 & 16 \\
\hline Q-Statistic & 31.34 & 31.34 & 31.349 & 31.350 & 31.371 & 31.384 & 31.422 & 31.44 & 31.441 & 31.443 & 31.46 & 31.462 & 31.509 & 31.566 & 31.608 & 31.619 \\
\hline$p$-value & 0.00 & 0.00 & 0.00 & 0.00 & 0.00 & 0.00 & 0.00 & 0.00 & 0.00 & 0.00 & 0.001 & 0.002 & 0.003 & 0.005 & 0.007 & 0.011 \\
\hline
\end{tabular}

Table 12. ACF test on absolute returns for guaranty trust.

\begin{tabular}{|c|c|c|c|c|c|c|c|c|c|c|c|c|c|c|c|c|}
\hline Lags & 1 & 2 & 3 & 4 & 5 & 6 & 7 & 8 & 9 & 10 & 11 & 12 & 13 & 14 & 15 & 16 \\
\hline $\mathrm{ACF}$ & 0.470 & 0.013 & 0.010 & 0.018 & 0.02 & 0.014 & 0.020 & 0.014 & 0.007 & 0.015 & 0.012 & 0.010 & 0.015 & 0.018 & 0.007 & 0.004 \\
\hline STDERR & 0.18 & 0.18 & 0.18 & 0.18 & 0.18 & 0.18 & 0.18 & 0.18 & 0.18 & 0.18 & 0.18 & 0.18 & 0.18 & 0.18 & 0.18 & 0.18 \\
\hline $\mathrm{df}$ & 1 & 2 & 3 & 4 & 5 & 6 & 7 & 8 & 9 & 10 & 11 & 12 & 13 & 14 & 15 & 16 \\
\hline Q-Statistic & 709.07 & 709.61 & 709.95 & 711.02 & 712.31 & 712.94 & 714.27 & 714.93 & 715.08 & 715.76 & 716.25 & 716.58 & 717.28 & 718.31 & 718.48 & 718.53 \\
\hline$p$-value & 0.00 & 0.00 & 0.00 & 0.00 & 0.00 & 0.00 & 0.00 & 0.00 & 0.00 & 0.00 & 0.00 & 0.00 & 0.00 & 0.00 & 0.00 & 0.00 \\
\hline
\end{tabular}

Table 13. ACF for absolute returns of first bank.

\begin{tabular}{|c|c|c|c|c|c|c|c|c|c|c|c|c|c|c|c|c|}
\hline Lags & 1 & 2 & 3 & 4 & 5 & 6 & 7 & 8 & 9 & 10 & 11 & 12 & 13 & 14 & 15 & 16 \\
\hline $\mathrm{ACF}$ & 0.196 & 0.006 & 0.30 & 0.005 & 0.001 & -0.004 & -0.005 & -0.003 & -0.005 & -0.003 & 0.003 & 0.004 & 0.000 & -0.004 & -0.001 & -0.001 \\
\hline STDERR & 0.018 & 0.018 & 0.018 & 0.018 & 0.018 & 0.018 & 0.018 & 0.018 & 0.018 & 0.018 & 0.018 & 0.018 & 0.018 & 0.018 & 0.018 & 0.018 \\
\hline df & 1 & 2 & 3 & 4 & 5 & 6 & 7 & 8 & 9 & 10 & 11 & 12 & 13 & 14 & 15 & 16 \\
\hline Q-Statistic & 122.895 & 123.015 & 411.203 & 411.27 & 411.28 & 411.32 & 411.40 & 411.44 & 411.51 & 411.54 & 411.57 & 411.64 & 411.64 & 411.68 & 411.68 & 411.683 \\
\hline$p$-value & 0.00 & 0.00 & 0.00 & 0.00 & 0.00 & 0.00 & 0.00 & 0.00 & 0.00 & 0.00 & 0.00 & 0.00 & 0.00 & 0.00 & 0.00 & 0.00 \\
\hline
\end{tabular}

Table 14. ACF for absolute returns of access bank.

\begin{tabular}{|c|c|c|c|c|c|c|c|c|c|c|c|c|c|c|c|c|}
\hline Lags & 1 & 2 & 3 & 4 & 5 & 6 & 7 & 8 & 9 & 10 & 11 & 12 & 13 & 14 & 15 & 16 \\
\hline $\mathrm{ACF}$ & 0.398 & 0.131 & 0.126 & 0.110 & 0.111 & 0.116 & 0.101 & 0.095 & 0.089 & 0.087 & 0.079 & 0.080 & 0.074 & 0.088 & 0.115 & 0.104 \\
\hline $\mathrm{df}$ & 1 & 2 & 3 & 4 & 5 & 6 & 7 & 8 & 9 & 10 & 11 & 12 & 13 & 14 & 15 & 16 \\
\hline STDERR & 0.018 & 0.018 & 0.018 & 0.018 & 0.018 & 0.018 & 0.018 & 0.018 & 0.018 & 0.018 & 0.018 & 0.018 & 0.018 & 0.018 & 0.018 & 0.018 \\
\hline $\begin{array}{c}\text { Q- } \\
\text { Statistic }\end{array}$ & 507.8 & 563.02 & 613.607 & 652.732 & 692.297 & 735.776 & 768.272 & 797.405 & 823.02 & 847.10 & 867.09 & 887.54 & 904.99 & 929.632 & 972.122 & 1006.68 \\
\hline$p$-value & 0.00 & 0.00 & 0.00 & 0.00 & 0.00 & 0.00 & 0.00 & 0.00 & 0.00 & 0.00 & 0.00 & 0.00 & 0.00 & 0.00 & 0.00 & 0.00 \\
\hline
\end{tabular}

Table 15. ACF of absolute returns for uba.

\begin{tabular}{|c|c|c|c|c|c|c|c|c|c|c|c|c|c|c|c|c|}
\hline Lags & 1 & 2 & 3 & 4 & 5 & 6 & 7 & 8 & 9 & 10 & 11 & 12 & 13 & 14 & 15 & 16 \\
\hline $\mathrm{ACF}$ & 0.474 & 0.004 & 0.017 & 0.028 & 0.018 & 0.012 & 0.017 & 0.012 & 0.003 & 0.003 & 0.008 & 0.004 & 0.011 & 0.024 & 0.007 & -0.005 \\
\hline DF & 1 & 2 & 3 & 4 & 5 & 6 & 7 & 8 & 9 & 10 & 11 & 12 & 13 & 14 & 15 & 16 \\
\hline Q-Statistic & 721.301 & 721.359 & 722.257 & 724.844 & 725.912 & 726.35 & 727.32 & 727.796 & 727.818 & 727.852 & 728.081 & 728.122 & 728.484 & 730.274 & 730.415 & 730.510 \\
\hline STDERR & 0.018 & 0.018 & 0.018 & 0.018 & 0.018 & 0.018 & 0.018 & 0.018 & 0.018 & 0.018 & 0.018 & 0.018 & 0.018 & 0.018 & 0.018 & 0.018 \\
\hline$p$-value & 0.00 & 0.00 & 0.00 & 0.00 & 0.00 & 0.00 & 0.00 & 0.00 & 0.00 & 0.00 & 0.00 & 0.00 & 0.00 & 0.00 & 0.00 & 0.00 \\
\hline
\end{tabular}




\subsection{Wider Implications of the Results for Theory and Practice}

We note that the commonly known stylized fact of non-normality of financial returns has implications for financial modelling, portfolio management, risk and general investment analysis [12] [48] [49] [50] [51]. One of the key implications is that, especially with smaller sample sizes which form the evidence base for some of the analysis, if the degree of non-normality is severe, classical normal-based procedures will be untenable. Alternative nonparametric procedures which are robust to non-normality then need to be explored. Moreover, non-normality is typically associated with thick tails in the underlying distributions, which determine the nature of risk calculus which will be suitable for hedging against losses in investment portfolios that incorporate the returns under consideration. This is the point of our earlier observation that a detailed analysis of the distributional properties of bank returns is a useful focus of future work. Related remarks regarding the implications of the volatility results are as follows.

Volatility modelling in the NSM and similar emerging markets is of increasing interest to (international) investors, financial institutions, policy makers and academics, for different and sometimes related reasons [10] [12] [38]. Investors search for arbitrage opportunities which relate to the observed or implied volatilities associated with key financial quantities and their derivatives, basically because high volatility means high risk and uncertainty, and therefore signals potentials for excessive gains or losses. These financial quantities include stock market indices, stock price returns, interest and exchange rates and commodity prices, for example oil prices in Nigeria, which correlate with key financial variables, given the country's heavy dependence on oil revenues, Omar [11]. Nigerian policy makers need to understand the volatilities in the financial system at overall market, sector- and company-specific levels, in order to gear monetary, macroeconomic and fiscal policies towards enhancement of economic performance, GDP growth, competitiveness and asset price stability, Aliyu [4]. Stock market analysts and policy makers in the Nigerian Stock Exchange (NSE) particularly need this understanding for effective stock market development. Academics study volatilities for all these reasons and in order to contribute to the literature on volatility modelling and financial market analyses, in such fields as empirical finance, financial economics, investments, financial risk management, and financial engineering. Despite not being a full study of bank volatility in Nigeria, the volatility results presented in this paper provide insights on how bank return performance could likely vary across periods characterised by bank reforms and global financial crisis, and by length of time involved. This prepares the ground for more detailed volatility modelling associated with the six empirical finance features mentioned above. These results will overall help to more systematically characterise the returns profiles of the banking sector which is the most important sector of the NSM. 
We further remark that most of the results obtained here are new in the sense that they are connected mainly to the stylized facts of bank returns, which have not been studied in this way in the volatility modelling of the NSM. Existing Nigerian studies are focused more on core volatility modelling which involves fitting different volatility models to data in different time periods [4] [5] [6] [12], for example. The results generally follow the non-normal, leptokurtic and sometimes asymmetric character of financial returns in most markets, especially emerging markets discussed in the literature review.

As noted earlier, the results obtained in this paper are based on the banking sector and complement to some extent overall market-based volatility results obtained by Ezepue and Omar [12]. The combined results from Ezepue and Omar [12], Omar [11] and this paper contribute useful new knowledge on the foundations of systematic stock market characterisation work, earlier anticipated in Ezepue and Omar [12], as opposed to the more traditional volatility modelling which dominate the received literature.

\section{Summary and Conclusions}

\section{Key Findings}

Daily stock returns of four major banks, Access, First bank, Guaranty Trust and United Bank for Africa (UBA) in Nigeria have been examined to see if the well documented and established stylized facts commonly are associated with the behaviour of short-interval asset returns, as reported for most major markets in the world, characterise the behaviour of the stocks traded by these banks within the NSM. From the price series, we obtain log returns as proxy for the asset return series for each bank, from which we computed absolute returns, squared returns mean-adjusted returns and mean-adjusted returns squared for the four banks. Our findings reveal that while the First bank and UBA returns are approximately symmetric, given their near zero-value for the coefficient of skewness, Access bank (with skewness of 1.597) could be said to be fairly symmetric, and Guaranty trust tends to be highly skewed (with skewness coefficient of 52.203; see Table 6).

Meanwhile, given high values of kurtosis, the banks could be said to be highly peaked, excessively leptokurtic with heavy tails (see Table 6), hence, non-normally distributed. The tests of Normality, those based on moments as well as that which is based on distribution reveal further the extent of deviation from normal distributions by the returns for these banks.

By these findings, we affirm that daily stock returns of Nigerian banks could not be described by a normal distribution. According to Koutmos et al. [52], the non-normality of the return distribution may be attributed partly to the presence of second-moment temporal dependencies in the stock returns. Additionally, Tables 8-11 as presented show that the autocorrelation functions (ACFs) in the daily returns for each of the banks is either negative or near-zero, which establishes the stylized fact that the series of daily returns are either negative or zero. 
However the tests of linear dependence in returns for these banks show some level of significance; also testing auto-correlation in volatility using absolute returns showed that there is high significant level of auto-correlation in volatility for the banks returns. The possible causes for the presence of dependence in the returns and its absolute value may be: 1) non-synchronous trading [53] and 2) time-varying short-term expected returns [54] [55]. The presence of serial auto-correlation in either absolute returns or mean-adjusted squared returns indicates the presence of long-range serial correlation in the returns volatility, which justifies our subsequent adoption of ARCH-GARCH family models for describing the volatility [52]. We also found that there exist high levels of volatility clustering in the return series of these banks, which became more pronounced during the global financial crises of 2007-2008 (see Figures 25-32).

Further empirical results include: 1) the returns of the four banks are leptokurtic, with fat tails, thus non-normal; 2) autocorrelations of daily returns are either negative or almost zeros at several lags; and 3) there is a positive and significant level of serial correlation in the absolute returns as well as in the higher order daily stock returns of each of the four banks. These serve to explain that statistical tests obtained via unconditional approach as well as the inferences drawn based on them might be misleading. Also, the presence of time dependence in the returns will help to produce reliable forecasts of the level, volatility and higher moments of the returns. Thus our findings have succeeded in establishing that stylized facts which are generally found to characterise daily returns of most stock markets are also present in the banking sector of NSM, thereby indicating that NSM is not a stand-alone market from the rest of the global market. Wider implications of the research results were discussed in Section 4.3 of the paper.

Some interesting lines of future work which will extend the initial results in this paper, and some of which are suggested by the reviewers, include: 1) more detailed analyses of returns distributions of Nigerian banks, using different types of univariate and multivariate probability models and their mixtures, including distributions that explore tail behaviours of returns and related risk factors; 2) discussion of the implications of these distributional characteristics for portfolio and risk management involving bank assets; and 3) doing these analyses and further empirical finance analyses of the banking sector (volatility, efficiency, bubbles, anomalies, valuation, and predictability), for different periods of reforms, financial policies and global financial crisis.

Related further work on the stability of the various return series over the different time regimes should involve the use of tail indices, similar to the analyses conducted by Hols and de Vries [56], Koedijk and Kool [57] and Loretan and Phillips [58]. It will be important to examine how all these characterisation results relate to the business models of the different banks, linked to their relative financial performance in these periods. The researchers are currently addressing some of these lines of analyses. 
In conclusion, the paper presents important foundational insights on the links between volatility of bank returns, the basic stylized facts, and anticipates more detailed characterisation of Nigerian banks' stock market performance in future studies, in a way that departs from the traditional approach of fitting volatility models to observed stock market data.

\section{Acknowledgements}

The authors are grateful to the anonymous reviewers whose comments have helped to improve this paper considerably.

\section{References}

[1] Yahaya, A. (2012) On Numerical Solution for Optimal Allocation of Investment Funds in Portfolio Selection Problem. CBN Journal of Applied Statistics, 3, 1-15.

[2] Musa, Y., Asare, B.K. and Gulumbe, S.U. (2013) Effect of Monetary-Fiscal Policies Interaction on Price and Output Growth in Nigeria. CBN Journal of Applied Statistics, 4, 55-74.

[3] African Development Bank (AFDB) (2007) Research Proposal on Financial Services and Economic Development: Case of SANE Countries (South Africa, Algeria, Nigeria and Egypt). ECON Unit, African Development, Tunisia.

[4] Aliyu, S.U.R. (2012) Reactions of Stock Market to Monetary Policy Shocks during the Global Financial Crisis: The Nigerian Case. CBN Journal of Applied Statistics, 3, $1-23$.

[5] Alade, S.O. (2012) Quality Statistics in Banking Reforms for National Transformation. CBN Journal of Applied Statistics, 3, 127-142.

[6] Ezeoha, A., Ogamba, E. and Okereke-Onyiuke, N. (2009) Stock Market Development and Private Investment Growth in Nigeria. Journal of Sustainable Development in Africa, 11, 20-35.

[7] Osinubi, T.S. (2004) Does Stock Market Promote Economic Growth in Nigeria? The ICFAI Journal of Applied Finance, 10, 17-35.

[8] Poon, S. and Granger, C.W.J. (2003) Forecasting Volatility in Financial Markets: A Review. Journal of Economic Literature, 41, 478-539. https://doi.org/10.1257/.41.2.478

[9] Ezepue, P.O. and Solarin, A.R.T. (2009) The Meta-Heuristics of Global Financial Crisis in the Eyes of the Credit Squeeze: Any Lessons for Modelling Emerging Financial Markets? In: Ale, S.O., et al., Eds., Proceedings of the 2008 International Conference on Mathematical Modelling of Global Challenging Problems in the $21^{\text {st }}$ Century, National Mathematical Centre, Abuja, Nigeria, 26-30 November 2008 278-288.

http://www.afrihero.org.uk/index.php?option=com_content\&view=article\&id=120 \&itemid $=85$

[10] Islam, S.M.N. and Watanapalachaikul, S. (2005) Empirical Finance: Modelling and Analysis of Emerging Financial and Stock Markets. Springer, New York.

[11] Omar, M.A.T. (2012) Stochastic Modelling in Financial Markets: Case Study of the Nigerian Stock Market. Doctoral Thesis, Sheffield Hallam University, Sheffield.

[12] Ezepue, P.O. and Omar, M.A.T. (2012) Weak-Form Market Efficiency of the Nigerian Stock Market in the Context of Financial Reforms and Global Financial Crisis. Journal of African Business, 13, 209-220. 
https://doi.org/10.1080/15228916.2012.727750

[13] Thompson, S. (2011) The Stylised Facts of Stock Price Movements. New Zealand Review of Economics and Finance, 1, 50.

[14] Taylor, J.W. (2005) Generating Volatility Forecasts from Value at Risk Estimates. Management Science, 51, 712-725. https://doi.org/10.1287/mnsc.1040.0355

[15] Cont, R. (2001) Empirical Properties of Asset Returns: Stylized Facts and Statistical issues. Journal of Quantitative Finance, 1, 223-236. https://doi.org/10.1080/713665670

[16] Mandelbrot, B. (1963) New Methods in Statistical Economics. Journal of Political Economy, 71, 421-440. https://doi.org/10.1086/258792

[17] Fama, E.F. (1965) The Behaviour of Stock Market Prices. Journal of Business, 38, 34-105. https://doi.org/10.1086/294743

[18] Nelson, D.B. (1991) Conditional Heteroscedasticity in Asset Returns: A New Approach. Econometrica: Journal of the Econometric Society, 59, 347-370. https://doi.org/10.2307/2938260

[19] Booth, G.G., Kaen, F.R., Koutmos, G. and Sherman, H.C. (2000) Bundesbank Intervention Effects through Interest Rate Policy. Journal of International Financial Markets, Institutions and Money, 10, 263-274. https://doi.org/10.1016/S1042-4431(00)00032-9

[20] Engle, R.F. (1982) Autoregressive Conditional Heteroskedasticity with Estimates of the Variance of U.K. Inflation. Econometrica, 50, 987-1008. https://doi.org/10.2307/1912773

[21] Bollerslev, T., Engle, R.F. and Nelson, D.B. (1994) ARCH Models. Handbook of Econometrics, 4, 2959-3038. https://doi.org/10.1016/S1573-4412(05)80018-2

[22] Koutmos, G. and Knif, J. (2002) Estimating Systematic Risk Using Time Varying Distributions. European Financial Management, 8, 59-73. https://doi.org/10.1111/1468-036X.00176

[23] Scruggs, J.T. and Glabadanidis, P. (2003) Risk Premia and the Dynamic Covariance between Stock and Bond Returns. Journal of Financial and Quantitative Analysis, 38, 295-316. https://doi.org/10.2307/4126752

[24] Black, F. (1976) Studies of Stock Price Volatility Changes. In: Proceedings of the 1976 Meetings of the American Statistical Association, Business and Economics Section, Chicago, IL, 177-181.

[25] Christie, A.A. (1982) The Stochastic Behaviour of Common Stock Variances: Value, Leverage and Interest Rate Effects. Journal of Financial Economics, 10, 407-432. https://doi.org/10.1016/0304-405X(82)90018-6

[26] Bekaert, G. and Wu, G.J. (2000) Asymmetric Volatility and Risk in Equity Markets. Review of Financial Studies, 13, 1-42. https://doi.org/10.1093/rfs/13.1.1

[27] Lebaron, B. (1992) Some Relations between Volatility and Serial Correlations in Stock Market Returns. Journal of Business, 65, 199-219. https://doi.org/10.1086/296565

[28] Campbell, J.Y., Grossman, S.J. and Wang, J. (1993) Trading Volume and Serial Correlation in Stock Returns. The Quarterly Journal of Economics, 108, 905-939. https://doi.org/10.2307/2118454

[29] Sentana, E. and Wadhwani, S. (1992) Feedback Traders and Stock Return Autocorrelations: Evidence from a Century of Daily Data. The Economic Journal, 102, 415-425. https://doi.org/10.2307/2234525 
[30] Koutmos, G. (1997) Do Emerging and Developed Markets Behave Alike? Evidence from Six Pacific-Basin Stock Markets. Journal of International Financial Markets Institutions and Money, 7, 221-234. https://doi.org/10.1016/S1042-4431(97)00022-X

[31] Harvey, C.R. (1995) Predictable Risk and Returns in Emerging Markets. The Review of Financial Studies, 8, 773-816. https://doi.org/10.1093/rfs/8.3.773

[32] Harvey, C.R. (1991) The World Price of Covariance Risk. The Journal of Finance, 46, 111-157. https://doi.org/10.1111/j.1540-6261.1991.tb03747.x

[33] Taylor, S.J. (2011) Asset Price Dynamics, Volatility and Prediction. Princeton University Press, Princeton, NJ. https://doi.org/10.1515/9781400839254

[34] Booth, G.G., Hatem, J., Virtanen, I. and Yli-Olli, P. (1992) Stochastic Modelling of Security Returns: Evidence from the Helsinki Stock Exchange. European Journal of Operational Research, 56, 98-106. https://doi.org/10.1016/0377-2217(92)90295-K

[35] Pagan, A. (1996) The Econometrics of Financial Markets. Journal of Empirical Finance, 3, 15-102. https://doi.org/10.1016/0927-5398(95)00020-8

[36] Richardson, M. and Smith, T. (1993) A Test for Multivariate Normality in Stock Returns. Journal of Business, 66, 295-321. https://doi.org/10.1086/296605

[37] Ding, Z.X., Granger, C.W.J and Engle, R.F. (1993) A Long Memory Property of Stock Market Returns and a New Model. Journal of Empirical Finance, 1, 83-106. https://doi.org/10.1016/0927-5398(93)90006-D

[38] Aggarwal, R., Inclan, C. and Leal, R. (1999) Volatility in Emerging Stock Markets. Journal of Financial and Quantitative Analysis, 34, 33-55. https://doi.org/10.2307/2676245

[39] Taylor, S.J. (2008) Modelling Financial Time Series. World Scientific, Singapore.

[40] JARQUE, Carlos M. and BERA, Anil K. (1980) Efficient Tests for Normality, Homoscedasticity and Serial Independence of Regression Residuals. Economics Letters 6, 255-259. https://doi.org/10.1016/0165-1765(80)90024-5

[41] Bera, A.K. and Jarque, C.M. (1981) Efficient Tests for Normality, Homoscedasticity and Serial Independence of Regression Residuals: Monte Carlo Evidence. Economics Letters, 7, 313-318. https://doi.org/10.1016/0165-1765(81)90035-5

[42] Doornik, J.A. and Hansen, H. (1994) An Omnibus Test for Univariate and Multivariate Normality (No. W4\&91). University of Oxford, Nuffield College, Economics Group, Oxford.

[43] Kolmogorov, A.N. (1933) Foundations of Probability. Springer-Verlag, Berlin.

[44] Conover, W.J. (1999) Statistics of the Kolmogorov-Smirnov Type. In: Practical Nonparametric Statistics, John Wiley \& Sons, New York, 428-473.

[45] Engle, R. (1995) ARCH: Selected Readings. Oxford University Press, Oxford.

[46] Corhay, A. and Rad, A.T. (1994) Statistical Properties of Daily Returns: Evidence from European Stock Markets. Journal of Business Finance \& Accounting, 21, 271-282. https://doi.org/10.1111/j.1468-5957.1994.tb00318.x

[47] Tsay, R. (2010) Analysis of Financial Time Series. 3rd Edition, John Wiley \& Sons, New York. https://doi.org/10.1002/9780470644560

[48] Mills, T.C. and Markellos, R.N. (2008) The Econometric Modelling of Financial Time Series. 3rd Edition, Cambridge University Press, Cambridge. https://doi.org/10.1017/CBO9780511817380

[49] Alexander, C. (2008) Quantitative Methods in Finance. John Wiley \& Sons, New York. 
[50] Forbes, C., Evans, M., Hastings, N. and Peacock, B. (2011) Statistical Distributions; 4th Edition, John Wiley \& Sons, New York.

[51] McNeil, A.J., Frey, R. and Embretchs, P. (2005) Quantitative Risk Management; Princeton University Press, Princeton, NJ.

[52] Koutmos, G., Pericli, A. and Trigeorgis, L. (2006) Short-Term Dynamics in the Cyprus Stock Exchange. European Journal of Finance, 12, 205-216. https://doi.org/10.1080/13518470500146074

[53] Fisher, L. (1966) Some New Stock-Market Indexes. The Journal of Business, 39, 191-225. https://doi.org/10.1086/294848

[54] Fama, E.F. and French, K.R. (1988) Permanent and Transitory Components of Stock Prices. Journal of Political Economy, 96, 246-273. https://doi.org/10.1086/261535

[55] Fama, E.F. and French, K.R. (1993) Common Risk Factors in the Returns on Stocks and Bonds. Journal of Financial Economics, 33, 3-56. https://doi.org/10.1016/0304-405X(93)90023-5

[56] Hols, M.C.A.B. and de Vries, C. (1991) The Limiting Distribution of Exchange Rate Returns. Journal of Applied Econometrics, 6, 287-302. https://doi.org/10.1002/jae.3950060306

[57] Koedijk, K. and Kool, C.J.M. (1992) Tail Estimates of East European Exchange Rates. Journal of Business and Economic Statistics, 10, 83-96.

[58] Loretan, M. and Phillips, P. (1994) Testing the Covariance Stationarity of Heavy-Tailed Time Series: An Overview of the Theory with Applications to Several Financial Datasets. Journal of Empirical Finance, 1, 211-248.

https://doi.org/10.1016/0927-5398(94)90004-3 


\section{Appendix A}

RETURNS

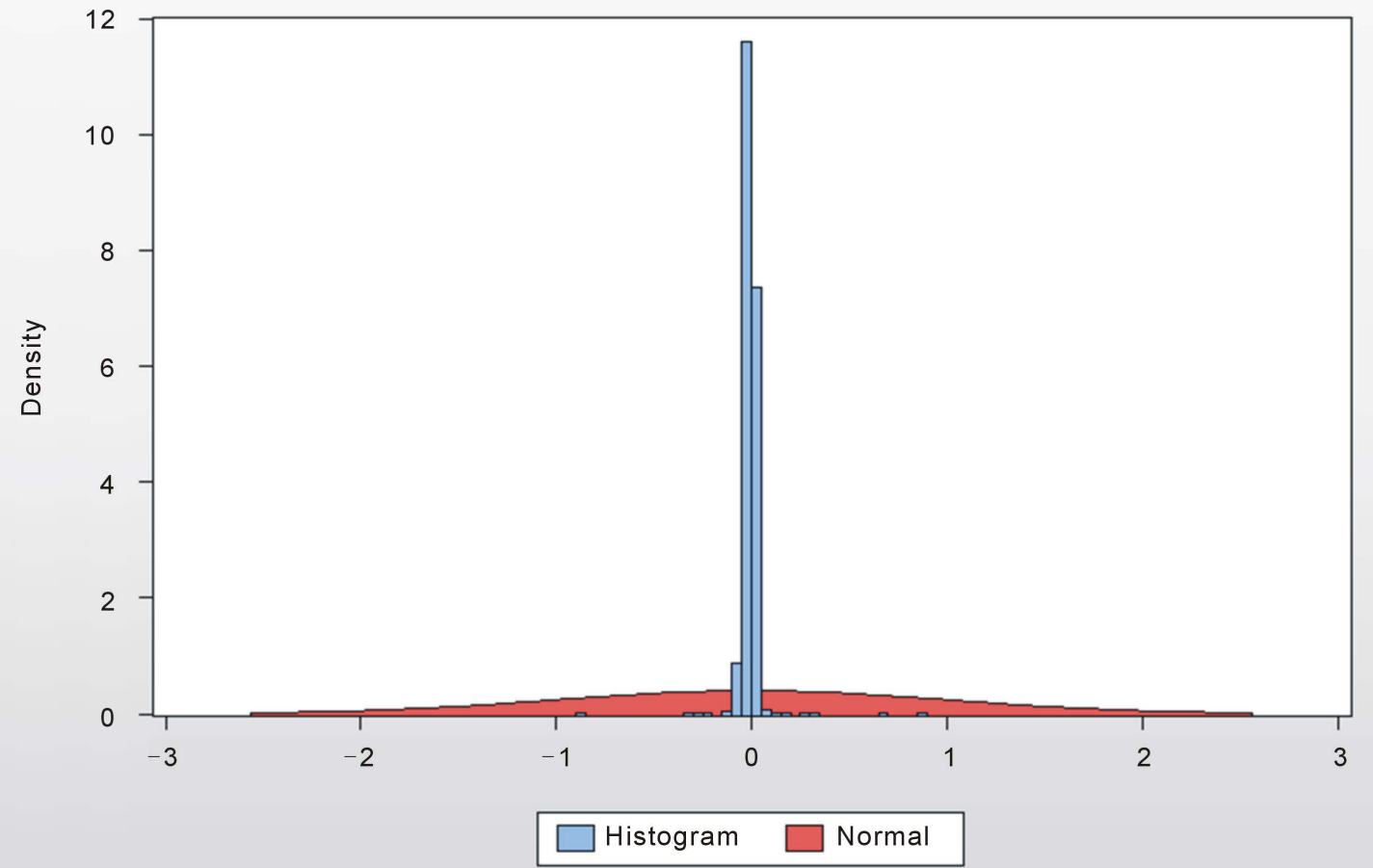

Figure A1. Access bank normal plot.

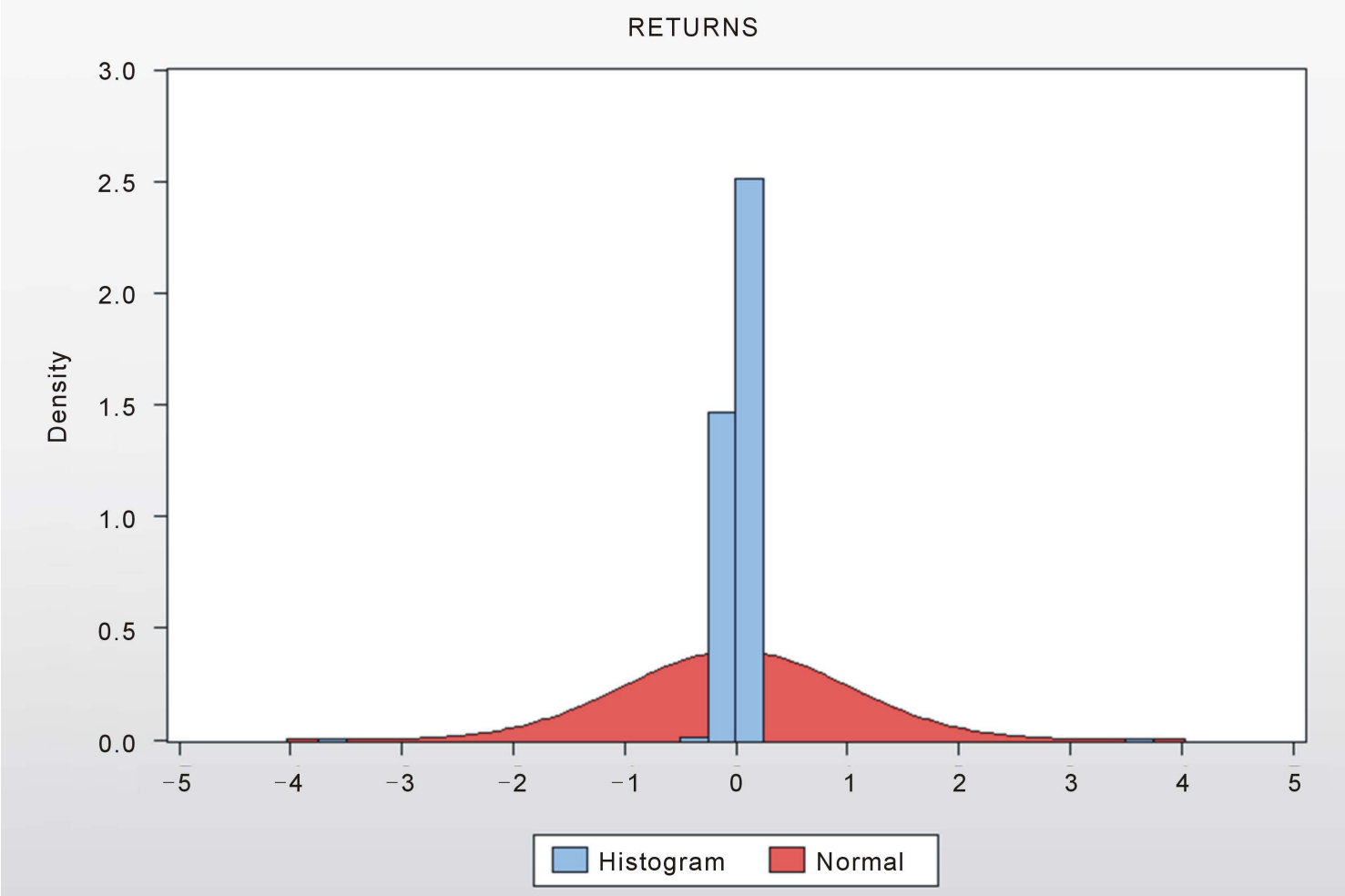

Figure A2. First Bank normal plot. 


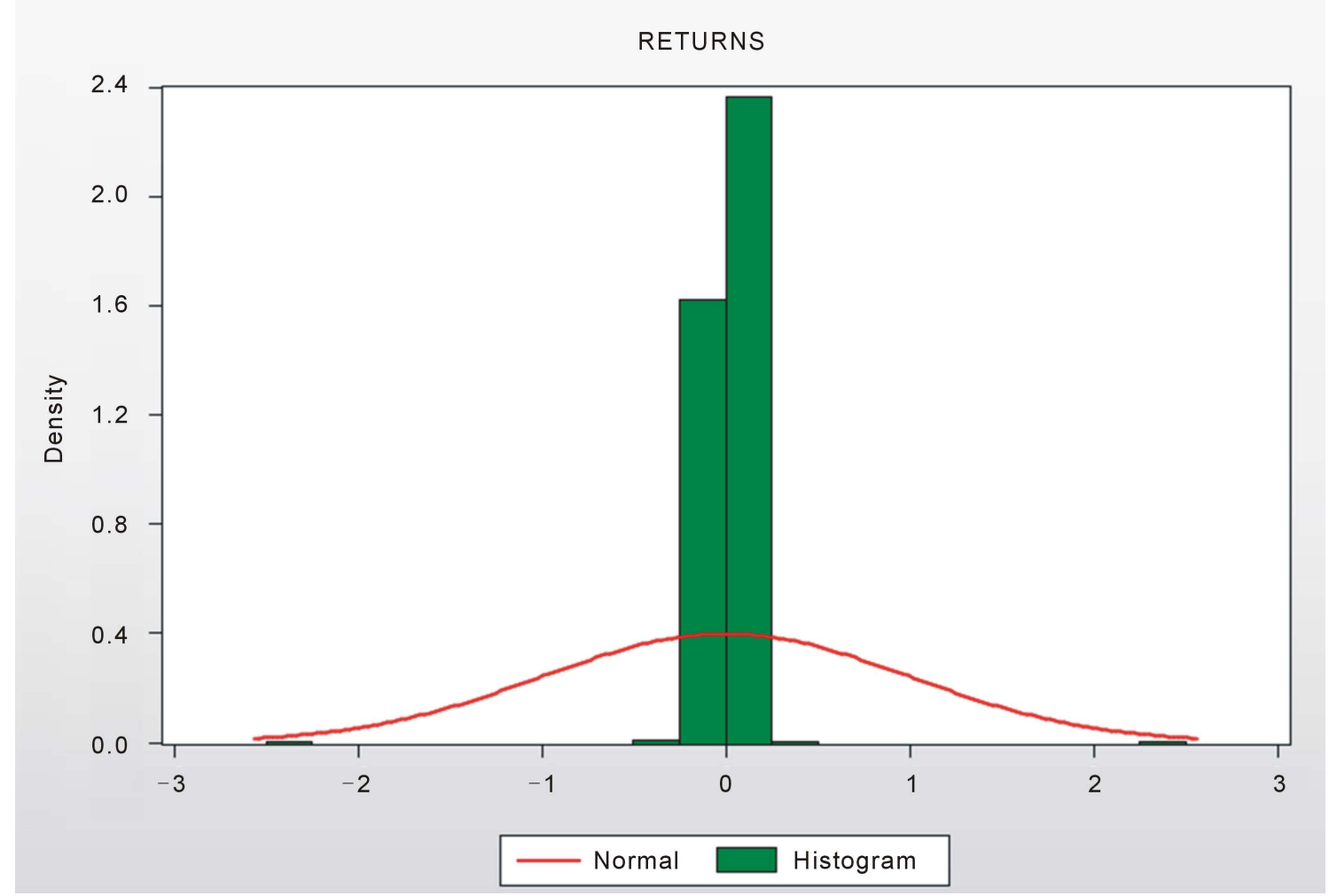

Figure A3. Normal plot for guaranty trust bank.

RETURNS

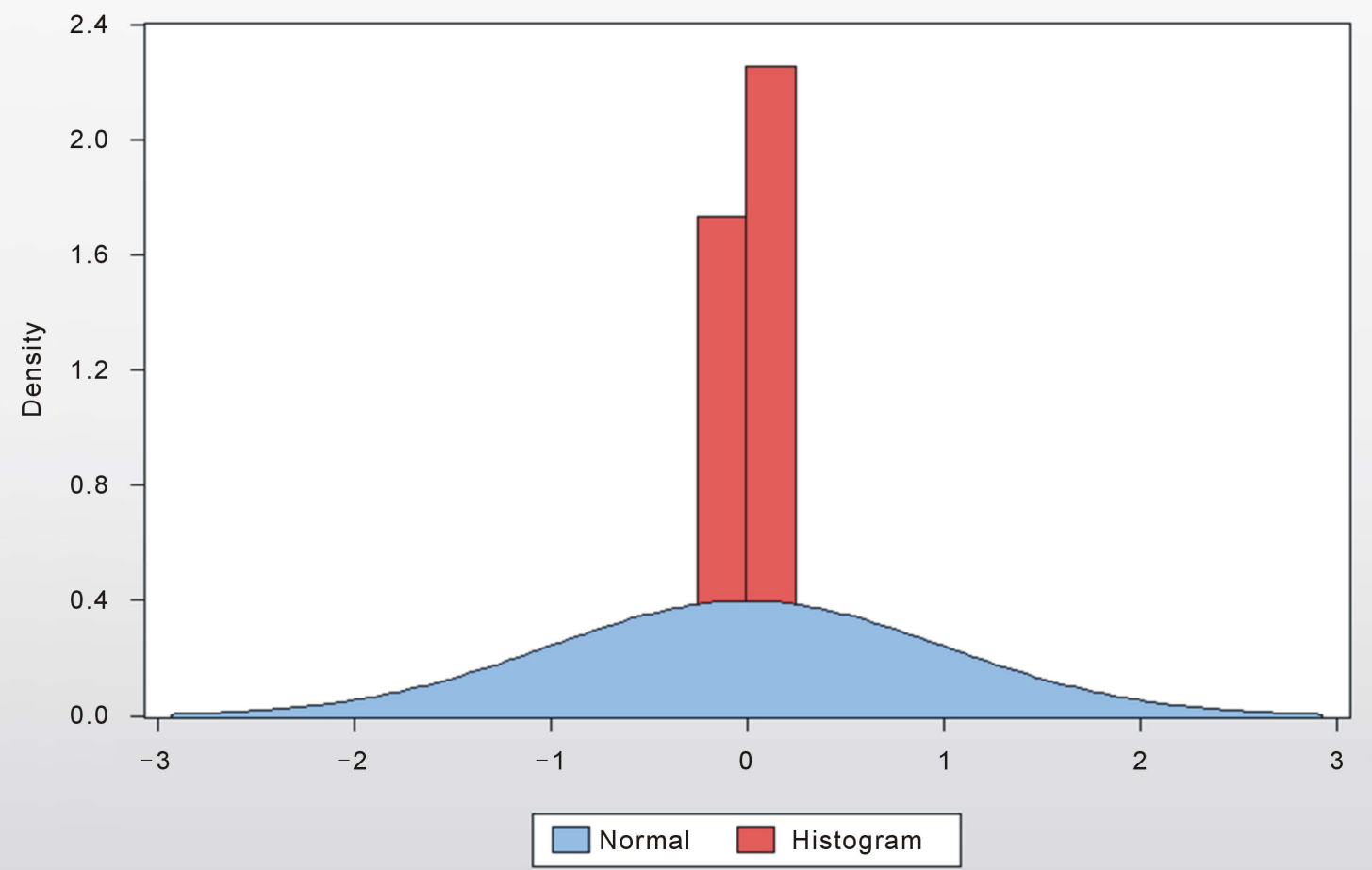

Figure A4. Normal plot for UBA. 


\section{Appendix B}

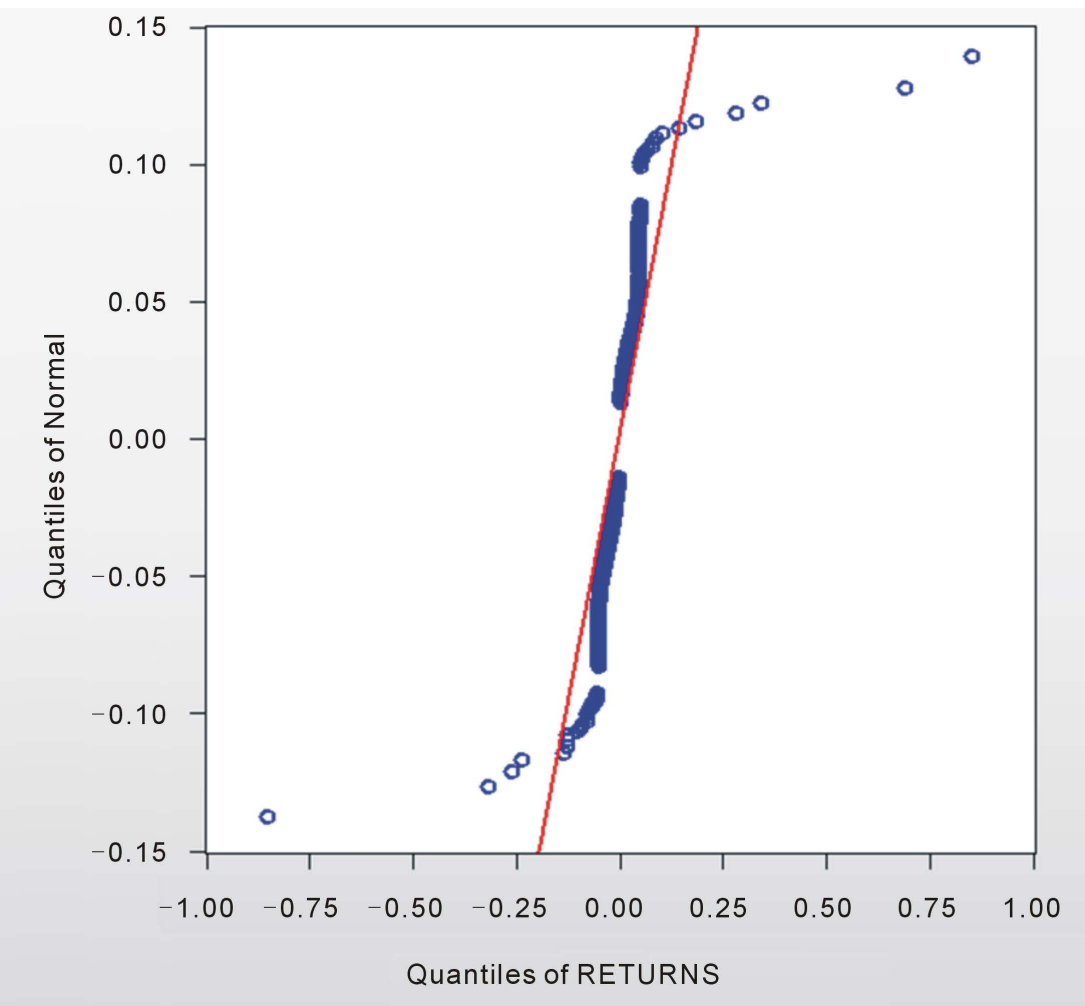

Figure B1. Q-Q plot of access bank.

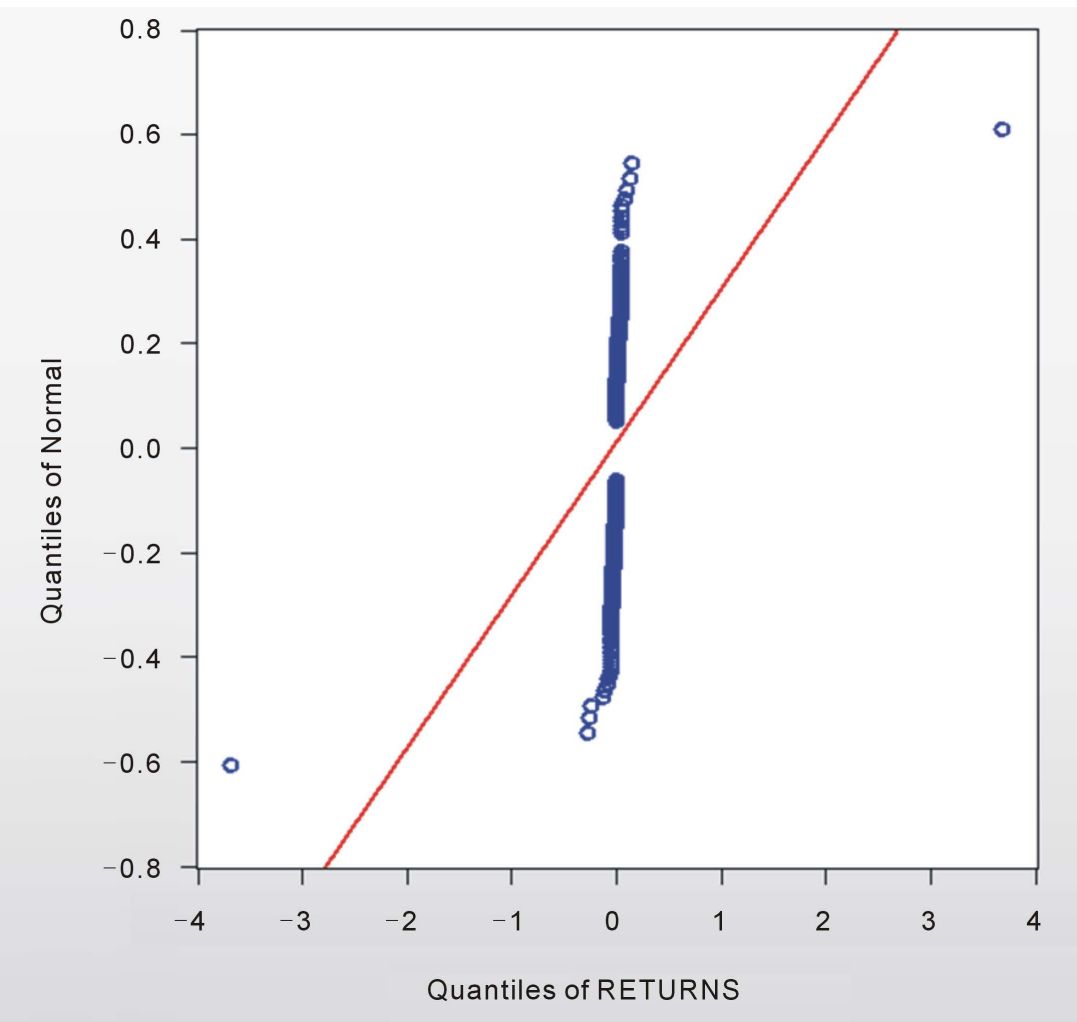

Figure B2. Q-Q plot for first bank. 


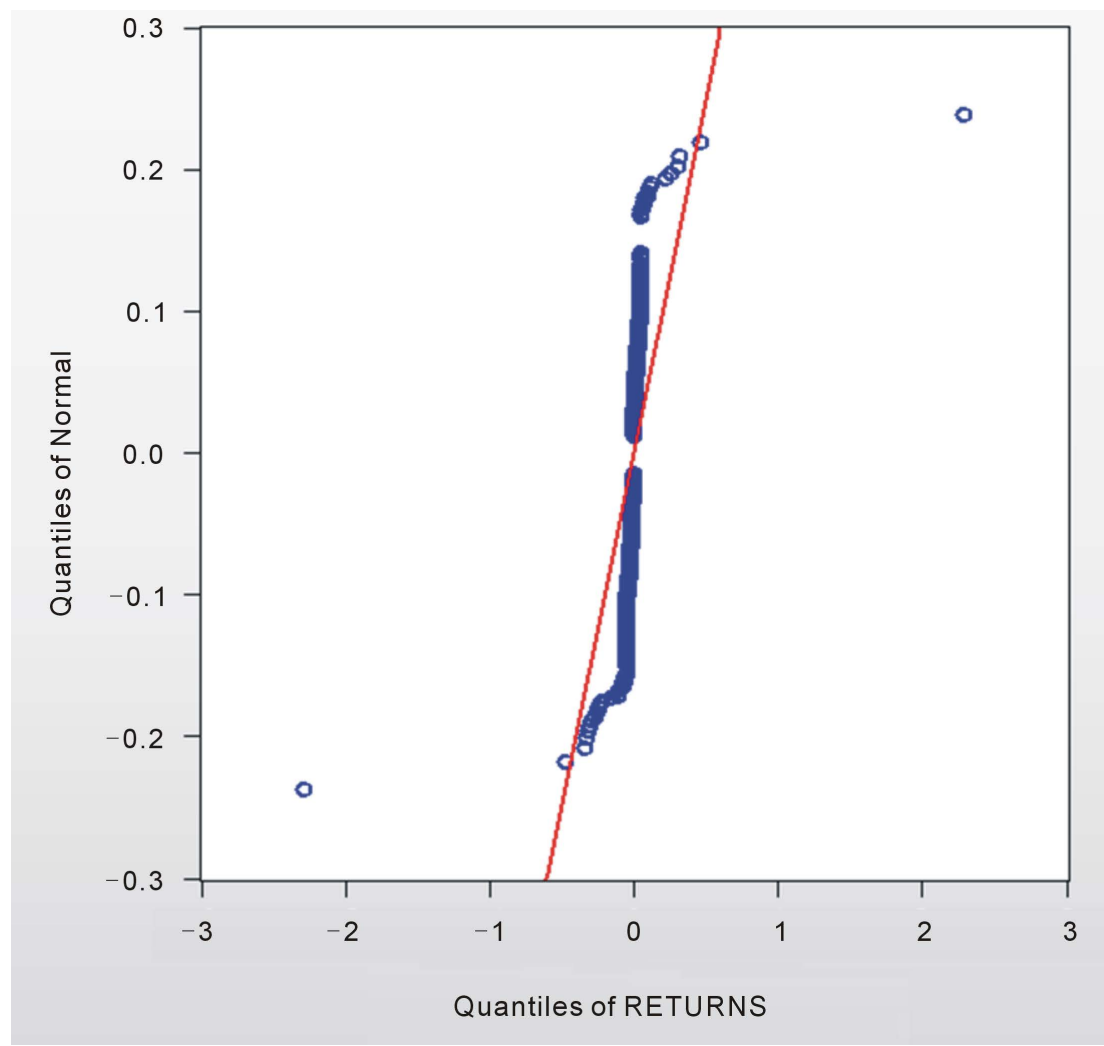

Figure B3. Q-Q plot for guaranty trust.

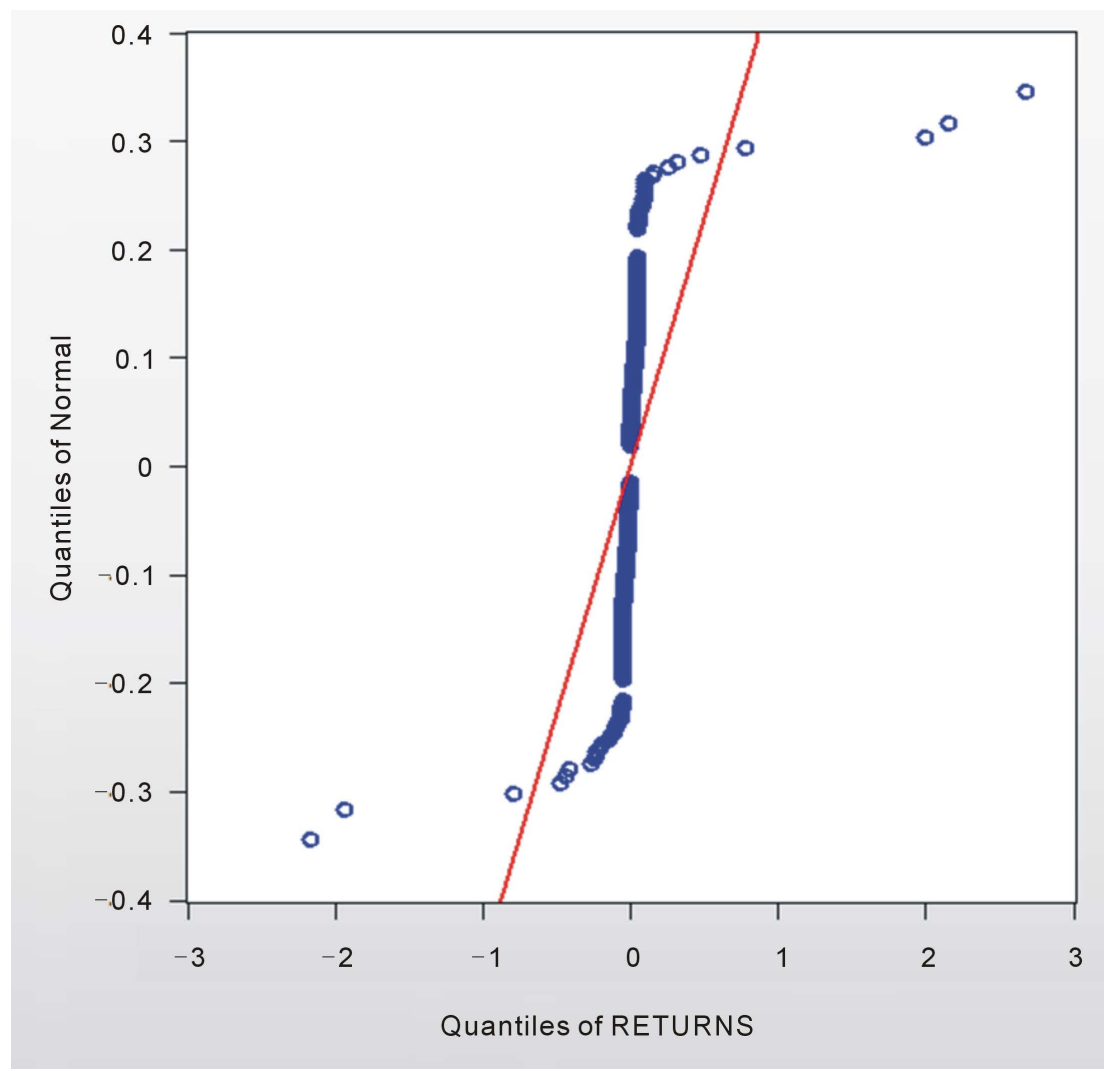

Figure B4. Q-Q Plot for UBA. 


\section{Appendix C}

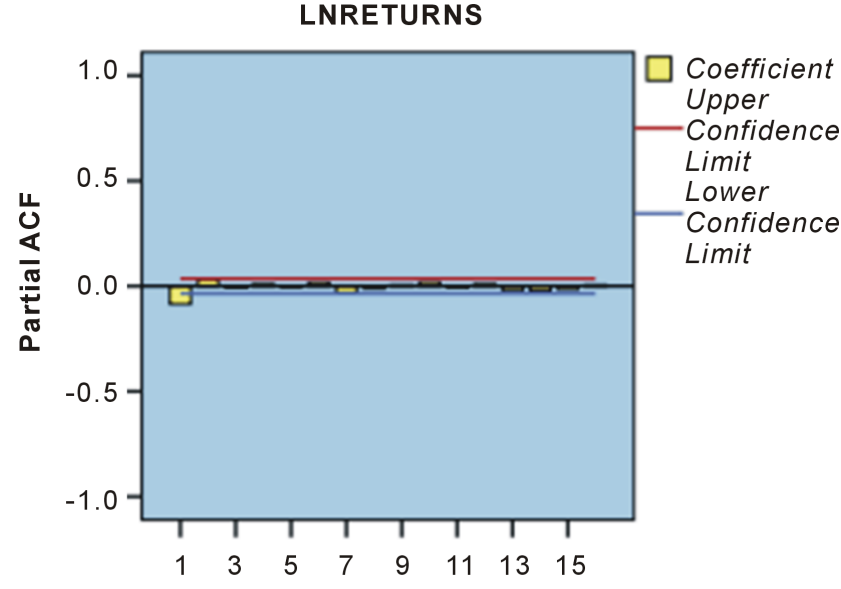

Lag Number

Figure C1. PACF of ACCESS bank daily log returns.

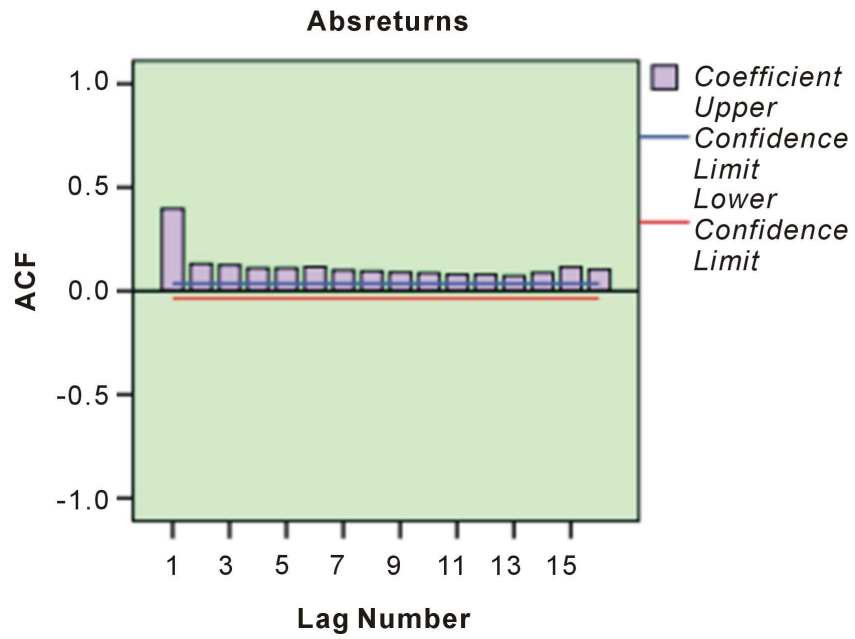

Figure C2. ACF of ACCESS bank daily absolute returns.

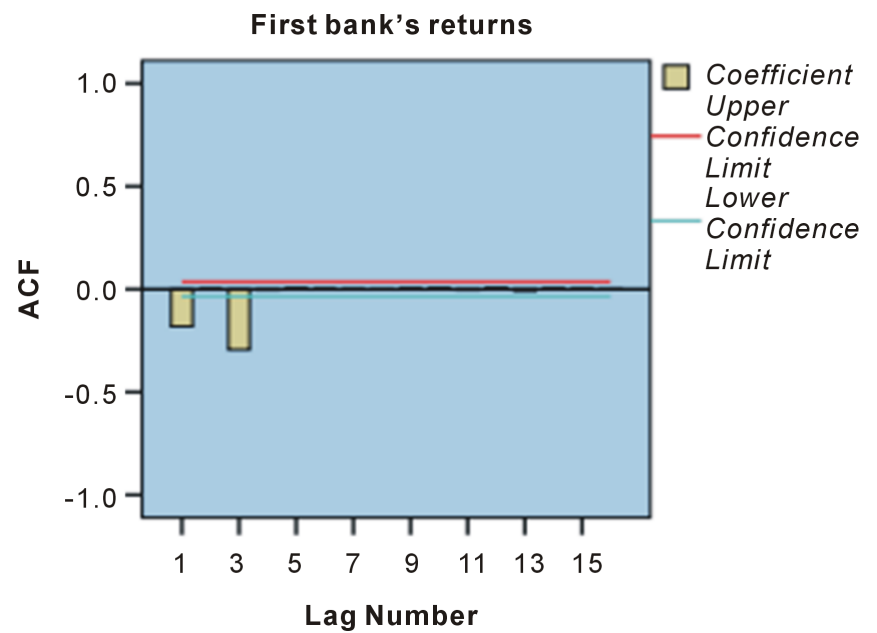

Figure C3. ACF of FIRST bank daily log returns. 


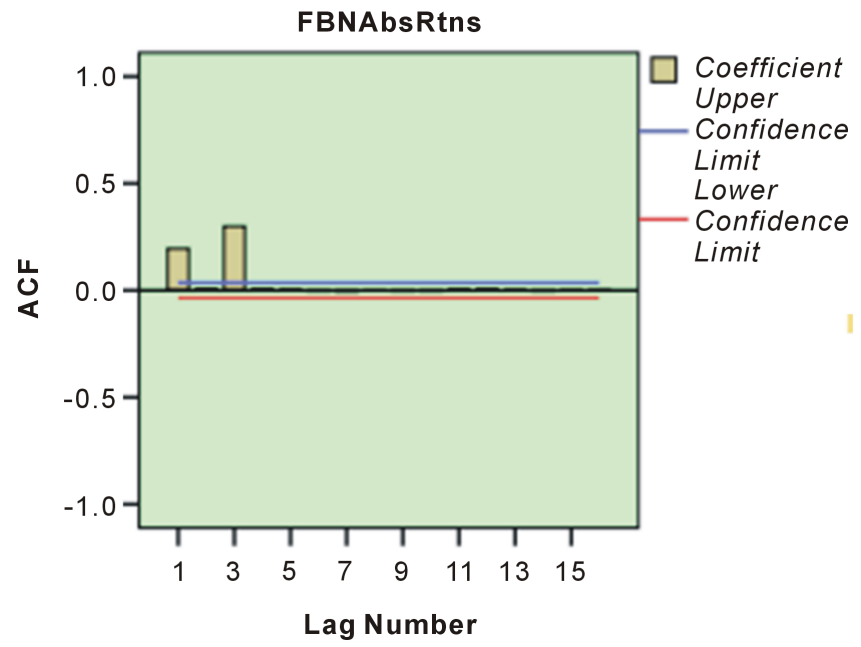

Figure C4. ACF of FIRST bank daily ABSOLUTE returns.

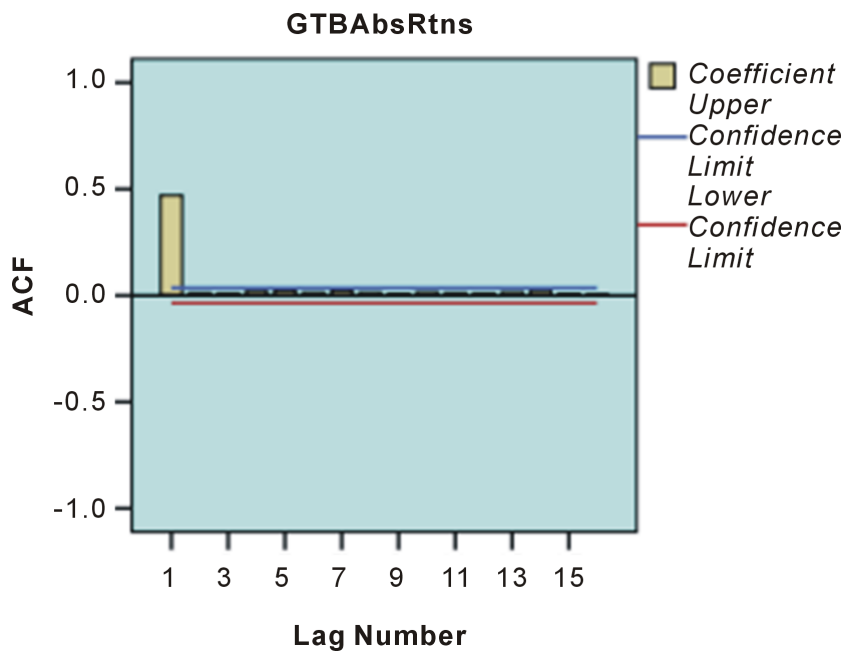

Figure C5. ACF of GUARANTY TRUST bank absolute daily returns.

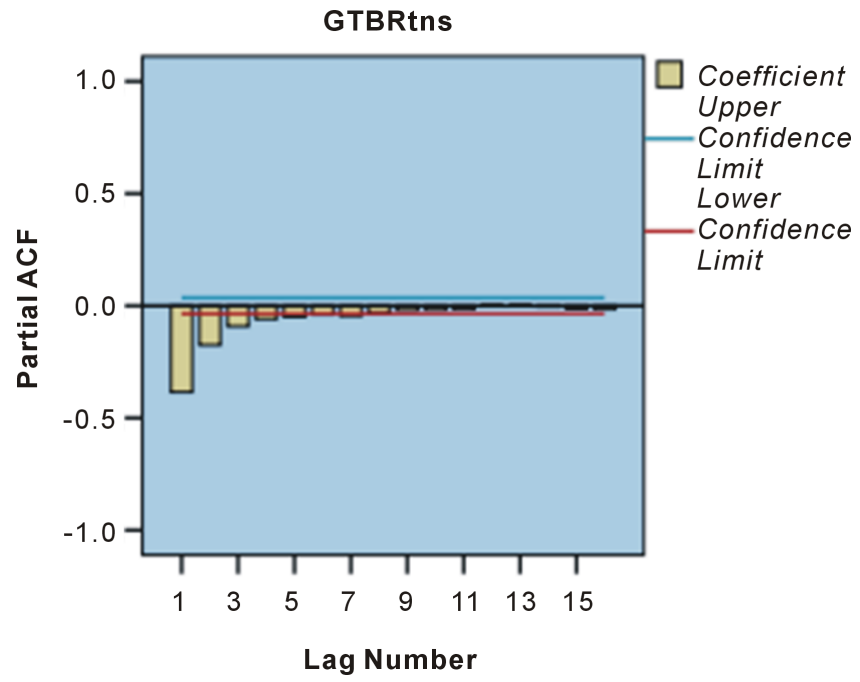

Figure C6. PACF of GUARANTY TRUST bank daily returns at lag 16. 